\title{
Intergroup cooperation prevents resource exhaustion but undermines intra- group cooperation in the common-pool resource experiment
}

\author{
Karolina Safarzynska ${ }^{1}$
}

\begin{abstract}
Can intergroup cooperation over resources help prevent resource exhaustion and mitigate effects of climate change? How does resource uncertainty affect inter- and intra- group cooperation over resources in the common-pool resource dilemmas? I present experimental evidence from a mixed design experiment with two-between-groups factors: (1) the availability of intergroup sharing in which subjects can decide whether to give up some of their harvests to augment the resource stock of another group; (2) the presence (or absence) of shocks that can destroy a part of resources; and with one within-groups factor (41 replications). We present the evidence that random shocks encourage resource conservation. In addition, we find that intergroup cooperation is frequent. Many groups establish reciprocal exchanges of resources, which reduces the probability of resource exhaustion. The possible explanation of the high frequency of intergroup sharing in my sample is inequality aversion and reciprocity. Such reciprocal exchanges turned out to be successful in preventing resource collapse in the absence of shocks. However, the data I present show the dark sides of intergroup sharing. Subjects, who shared resources with the outgroup, harvested more for themselves following the donation. Moreover, under uncertainty, a combination of shocks and sharing made subjects overharvest resources.
\end{abstract}

Key Words: climate change; common pool resources; intergroup cooperation

\section{INTRODUCTION}

It is urgently necessary to prevent degradation of the environment. Many renewable resources are under threat or in a state of decline (Copeland and Taylor 2009). Results from field studies have shown that many communities self-organize and design effective institutions so as to prevent resource exhaustion (Ostrom 1992, 2006, Sigmund et al. 2010, Janssen et al. 2011). Studies of common-pool resource dilemmas (CPR) analyze harvesting decisions within groups in repeated games, thus in the absence of any spillover between groups. This is surprising, as $85 \%$ of Africa's water resources are composed of large river basins that are shared between several countries (Ashton 2002). Moreover, it is increasingly recognized that sustainability challenges require cooperation dilemmas to be addressed at multiple levels, for instance between individuals, groups, and populations (Waring et al. 2015).

Can intergroup cooperation mitigate the impacts of climate change? Will subjects help outgroup members whose resources are on the verge of ecological collapse? To answer these questions, I propose an experimental research design to examine the effects of resource uncertainty and intergroup cooperation on harvesting and the probability of resource exhaustion in the CPRs. Formally, I present experimental evidence from a mixed-design experiment with two between-group factors: (1) the presence (or absence) of shocks that can destroy part of the resources; (2) the availability of intergroup sharing; and one within-group factor (41 replications). I provide novel evidence that intergroup sharing can prevent resource exhaustion under resource certainty. This effect does not hold under resource uncertainty. A combination of shocks and intergroup sharing undermines intra-group cooperation, i.e., resource conservation within groups.

The approach was motivated by the fact that the intensity and severity of natural disasters is expected to increase in the coming years because of climate change (IPCC 2007). There are concerns that climate change will escalate the scarcity of renewable resources. Much has been written about the impact of climate change on resource conflicts (Ember and Ember 1992, Mwiturubani 2010, Downing et al. 2014; Harari and La Ferrara 2014, unpublished manuscript). Intergroup competition has also achieved a lot of attention in the theoretical and experimental literature (e.g., Bornstein 2003, Tan and Bolle 2007, Abbink et al. 2010). Far less attention has been devoted to intergroup cooperation, especially in CPR studies. This is surprising because evidence from the past five decades shows that the number of cooperative events far outweighs the number of conflicts over resources such as water (Wolf 2007).

Cooperation over resources between communities is common and can take various forms. For instance, in the past, the sharing of harvests by Native Americans on the Pacific Northwest coast has been an important strategy to prevent conflicts among them (Johnsen 2009). Another example, in Kenya, shows that groups suffering a dry period send some of their cattle to graze on the lands of other groups that have better weather conditions (McAllister et al. 2006). In this context, intergroup cooperation can be seen as a means of preventing conflicts or coping with environmental risk. So far, we know surprisingly little about how intergroup cooperation arises and affects in-group harvesting and the probability of resource exhaustion. My research aims to fill this gap.

I report the results of a laboratory experiment in which subjects decide how many resources to harvest from the common pool of resources. In particular, in the baseline scenario, subjects harvest resources repeatedly within groups from a renewable resource, which regrows according to the logistic curve. Subjects face the temptation to maximize their harvests to accumulate more profit. However, if the resource is exhausted, everyone in the group loses 
his/her payoffs. At the beginning of each session, groups are matched in pairs, which I refer to as "partner groups." In this context, I studied how harvesting is affected by random shocks that diminish resources. Shocks can, for instance, take the form of weather shocks or climatic events capable of destroying all, or part of, the common-pool resources.

In the sharing treatment, after harvesting, subjects can decide whether to send some of their harvests to augment the resources of the partner group. The reader may think of this treatment as subjects investing their own payoffs to finance technology, which improves the productivity of the resources of the partner group, thus acting as a form of agricultural aid. Currently, aid directed to the agricultural sector represents $4 \%$ of official development aid (ODA) from all donors (Kaya et al. 2013). Alternatively, it can take the form of groups of pastoralists who allow outgroup members to use their land, which can be interpreted as increasing the productivity of the land of the outgroup. The empirical importance of reciprocal grazing agreements has been well documented. For instance, reciprocity arrangements are common among pastoral herders in East Africa: if conditions are poor for one community, some of their herds are moved to the more productive lands of a distant partnering community (Dixit et al. 2013). Many groups establish reciprocal exchanges of resources, which prevents resource exhaustion under resource certainty. I discuss two possible explanations of the results: inequality aversion and reciprocity.

The formal approach presented is related to the theoretical and experimental literature on the effect of environmental uncertainty on the equilibrium outcomes in common-pool resource games (Budescu et al. 1992, 1995, Rapoport et al. 1992, 1993, Biel and Garling 1995, Hine and Gifford 1996, Botelho et al. 2014, Aflaki 2013 Antoniadou et al. 2013, Kimbrough and Wilson 2013, Safarzynska 2013, Schill et al. 2015, Blanco et al. 2016, 2017). In a standard harvesting set-up, individuals request resources from the common pool (e.g., Rapoport et al. 1992). Resources are drawn from a uniform distribution pool in each period. If the total individual extractions exceed the amount of resources, resources are destroyed and players receive nothing. Otherwise, players receive amounts equivalent to their individual requests. Rapoport and his coauthors show that if the risk associated with the resource size is high enough, this can lead to more consumption. In the discussed setting, the availability of resources in the future is independent of current decisions. This approach fails to capture the important aspects of the dynamics of resources, like groundwater systems, fisheries and forests (Botelho et al. 2014). In my experiment, resources are renewable, and thus the decisions of subjects in the current period affect the renewal rate of resources in future periods. I found that in this setting, uncertainty makes subjects conserve resources. My findings are similar to the results from the experiment by Schill et al. (2015) in which there is uncertainty concerning the renewal rate of the renewable resource. Communication was key to determining whether risk promotes cooperation in my experiments. I show that, even in the absence of communication, shocks encourage resource cooperation. Shocks increase the probability of resource collapse, which can only be reduced by groups constraining their harvests.
Finally, my research is also related to the literature on giftexchange and risk pooling. In a simple gift-exchange setting, a principal offers part of his endowment to an agent, who in turn is obliged to choose a certain level of effort. A higher effort is more beneficial for the principal, but is more costly for the agent. The evidence from gift-exchange experiments indicates that many subjects behave reciprocally, contrary to the predictions from economic models based on the assumption of rational and selfish agents (e.g., Fehr et al 1993, 1998a, 1998b, Fehr and Falk 1999). Typically, experimental games are played between individuals, not groups. A few studies show that groups are less cooperative than individuals. For instance, offers in the dictator games are substantially lower if the game is played between groups rather than between individuals (Bornstein and Yaniv 1998). As another example, Kocher and Sutter (2007) expanded the gift-exchange game to study group behavior. The authors found a considerable level of reciprocity in games with group decision making. Groups correctly anticipate that other groups will reciprocate their generous transfers. My results support these findings in the context of CPRs. I compare donations in the absence and presence of random shocks, showing that intergroup help under risk can crowd out the intrinsic motivation to conserve resources. My work also relates to the literature on risk pooling within groups, which I expand to the intergroup context. Recently, Cherry et al., (2015) examined whether subjects are willing to share their payoffs with other members of their group who lost some endowments because of the idiosyncratic shock. The authors report high levels of intragroup sharing, which reduce the variance of individual earnings.

\section{DESIGN OF EXPERIMENT AND THEORETICAL PREDICTIONS}

The experiment was conducted in Warsaw and Vienna: 144 students were recruited at the University of Warsaw and 96 students at the University of Vienna. Students earned on average about $€ 11.87$ per experiment in Vienna and PLN46.71 ( $€ 11.67$; PLN = Polish Zloty) in Warsaw. This includes a show-up fee, which was PLN5 in Poland (the exchange rate at the time was about $€ 1=$ PLN4), and subjects could earn between PLN5 and PLN20 in the IQ test preceding the experiment. In Vienna, the show-up fee was $€ 2$, and subjects could earn between $€ 1$ and $€ 7.5$ in the IQ test. The experiment was programmed and conducted using the software z-TREE (Fischbacher 2007). The experimental data can be accessed from https://osf.io/xf $72 \mathrm{~m} /$. There were no significant differences in the gender composition between the two samples: females constituted $54 \%$ and $45 \%$ of subjects in Austria and in Poland, respectively. The difference is not statistically significant according to the Mann-Whitney test. Participants were slightly older in Vienna, where the mean age was 25.52. In Warsaw, students were on average 23.54 years old. This difference is statistically significant, according to the Mann-Whiney test ( $p$ $<0.001)$.

The experiment has four treatments. In the baseline treatment, subjects harvest resources repeatedly from the common pool of resources. In the shock treatment, the possibility of random shocks, which can destroy part of the resources, is added. In the two other treatments, i.e. sharing and "sharing and shock", subjects could donate some of their harvests to augment the resources of the outgroup. In the sharing and shock treatment, the availability of sharing and the possibility of shocks are 
Table 1. Mean statistics. Standard deviation in brackets. $\mathrm{PL}=$ Poland, $\mathrm{AT}=$ Austria.

\begin{tabular}{|c|c|c|c|c|c|}
\hline Treatment & & Baseline & Shocks & Sharing & $\begin{array}{c}\text { Sharing and } \\
\text { Shocks }\end{array}$ \\
\hline \multirow[t]{2}{*}{ Number of students } & PL & 48 & 48 & 48 & \\
\hline & AT & 24 & 24 & 24 & 24 \\
\hline Number of sessions & & 3 & 4 & 4 & 1 \\
\hline \multirow[t]{2}{*}{ Probability of preventing resource exhaustion } & PL & 0.9 & 0.8 & 0.7 & \\
\hline & AT & 0.5 & 0.5 & 1 & 0.63 \\
\hline \multirow[t]{2}{*}{ Total payoffs } & PL & $\begin{array}{l}17.94 \\
(1.79)\end{array}$ & $\begin{array}{l}16.12 \\
(2.17)\end{array}$ & $\begin{array}{l}21.25 \\
(1.33)\end{array}$ & \\
\hline & AT & $\begin{array}{l}12.26 \\
(6.50)\end{array}$ & $\begin{array}{l}12.96 \\
(5.33)\end{array}$ & $\begin{array}{c}26.2 \\
(1.48)\end{array}$ & $\begin{array}{l}12.40 \\
(4.60)\end{array}$ \\
\hline \multirow[t]{2}{*}{ Mean fraction of harvested resources (by subjects) } & PL & $\begin{array}{c}0.05 \\
(0.03)\end{array}$ & $\begin{array}{c}0.04 \\
(0.03)\end{array}$ & $\begin{array}{c}0.07 \\
(0.06)\end{array}$ & \\
\hline & AT & $\begin{array}{c}0.05 \\
(0.04)\end{array}$ & $\begin{array}{c}0.04 \\
(0.03)\end{array}$ & $\begin{array}{c}0.04 \\
(0.02)\end{array}$ & $\begin{array}{c}0.09 \\
(0.08)\end{array}$ \\
\hline \multirow[t]{2}{*}{ Mean resources over time ${ }^{\dagger}$} & PL & $\begin{array}{c}7.82 \\
(4.45)\end{array}$ & $\begin{array}{l}13.71 \\
(7.59)\end{array}$ & $\begin{array}{l}12.89 \\
(8.42)\end{array}$ & \\
\hline & AT & $\begin{array}{l}13.08 \\
(9.86)\end{array}$ & $\begin{array}{c}18.42 \\
(11.98)\end{array}$ & $\begin{array}{l}17.59 \\
(8.02)\end{array}$ & $\begin{array}{l}12.88 \\
(3.77)\end{array}$ \\
\hline \multirow[t]{2}{*}{ Mean resources in the last period } & PL & $\begin{array}{c}4.40 \\
(5.99)\end{array}$ & $\begin{array}{l}10.40 \\
(6.89)\end{array}$ & $\begin{array}{l}8.88 \\
(9.50)\end{array}$ & \\
\hline & AT & $\begin{array}{c}10.97 \\
(10.04)\end{array}$ & $\begin{array}{c}15.07 \\
(17.49)\end{array}$ & $\begin{array}{l}11.79 \\
(8.10)\end{array}$ & $\begin{array}{c}6.23 \\
(4.19)\end{array}$ \\
\hline \multirow[t]{2}{*}{ Frequency of intergroup sharing resources } & PL & & & $\begin{array}{c}0.21 \\
(0.18)\end{array}$ & \\
\hline & AT & & & $\begin{array}{c}0.52 \\
(0.22)\end{array}$ & $\begin{array}{c}0.49 \\
(0.38)\end{array}$ \\
\hline \multirow[t]{2}{*}{$\begin{array}{l}\text { Mean number of periods before collapse in groups that exhausted } \\
\text { resources }\end{array}$} & PL & $\begin{array}{c}19.5 \\
(19.03)\end{array}$ & $\begin{array}{l}20.25 \\
(15.11)\end{array}$ & $\begin{array}{c}15.4 \\
(10.06)\end{array}$ & \\
\hline & AT & $\begin{array}{c}23 \\
(7.75)\end{array}$ & $\begin{array}{l}16.57 \\
(11.50)\end{array}$ & $\begin{array}{l}\text { N/A as no } \\
\text { group } \\
\text { exhausted } \\
\text { resources }\end{array}$ & $\begin{array}{c}7 \\
(1.73)\end{array}$ \\
\hline \multirow[t]{2}{*}{ The frequency of shocks } & PL & & $\begin{array}{l}0.25 \\
(0.06)\end{array}$ & & \\
\hline & AT & & $\begin{array}{l}0.26 \\
(0.05)\end{array}$ & & $\begin{array}{c}0.26 \\
(0.11)\end{array}$ \\
\hline
\end{tabular}

combined. For each treatment, the results from two sessions (each with 24 students) in Poland, and one in Vienna, are reported. There are two exceptions to this rule. In Poland, 3 sessions of the sharing treatment (with 18,18 , and 12 students, respectively) were conducted and 3 sessions of shock treatment (with 24, 18, and 6 students, respectively) because of the low show-up rate during earlier sessions. Moreover, the sharing and shock treatment was only conducted in Vienna. Each student only participated in one session. Table 1 provides an overview of the different treatments and reports the mean statistics.

The set-up of the experiment was the same in Austria and Poland. In each session, participants were randomly seated in front of computers with partitions between them. The identities of the group members were not revealed to participants. Each session was divided into four parts. In the first part, information was collected on the participants' risk aversion, their ability to solve the cognitive ability test, which we refer to as the IQ test, how much participants would donate to another (unknown) person in the room in the dictator game, and how much participants would donate to another person in the room knowing that this person would be given the opportunity to send them back some money in the trust game (for details see Appendix 1, C). I used the collected information as control variables in the statistical analysis. I found no statistically significant differences between Austrian and Polish samples concerning these variables, with the exception of risk. Polish participants were willing to donate more money to the risky project than Austrians, whereby the difference was statistically significant according to the Mann Whitney test $(\mathrm{p}<0.001)$.

In the second part, students were given the opportunity to learn the dynamics of the game in 10 rounds of training. Students were divided into eight groups (each consisting of three persons). They were not informed about the identity of the other group members. Each group had access to its own renewable resource, equal initially to 45 tokens. The subjects harvested resources repeatedly from the common pool of resources. During the round of training, subjects could learn the dynamics of resources, i.e., how resources change because of harvesting by group members. Participants were informed that they would not receive any monetary compensation for their performance in this part of the experiment. 
The second part was followed by the actual experiment. Students were rematched after training to form new groups of three persons. To account for possible dependencies in behavior created by this (i.e., the behavior of members of their training group could affect subjects' behavior in the actual game), I control for the outcomes of the rounds of training in the statistical analysis. Each newly formed group had access to 45 tokens in the common pool, from which group members were asked to harvest resources. Subjects were informed that for each collected token they would receive $€ 0.5$ in Austria and PLN1.5 in Poland. During the rounds of training, all students played the baseline game, whereas the actual experiment involved either the baseline game again or the baseline game with additional elements depending on the treatment, namely shocks or/and sharing. During this part of the experiment, subjects could observe the harvesting decisions and resources in their own group and in the partner group. The actual experiment lasted for 41 periods. Students were not informed about the exact number of rounds, only that the experiment would not exceed a total of two hours. This way the end-of-round effect, likely to occur when the number of rounds and their length are known in advance to participants (for a discussion on this, see Janssen 2010), was avoided. The condition of an infinitely repeated game is often induced in the lab by having a random continuation rule: after each round, the computer decides whether to finish the repeated game. However, introducing the continuation probability, which stops the game at any time, would prevent me from assessing how long it takes for groups to exhaust resources. Finally, in the third part, students answered some follow-up questions.

\section{Baseline treatment}

In the baseline treatment, subjects decide how many resources to harvest from the common pool of resources each round. The initial level of resources was equal to $R_{0}=45$. Afterward, resources were diminished by the total harvests $\mathrm{X}_{\mathrm{i}}=\Sigma \mathrm{x}_{i t}$, which are equal to the sum of the individual extractions $x_{i t}$, while the resources regrew according to the logistic equation: $R_{t+1}=R_{t}+$ $\mathrm{rR}_{\mathrm{t}}\left(1-\mathrm{R}_{\mathrm{t}} / \mathrm{K}\right)-\mathrm{X}_{\mathrm{t}}$, where $0<r<1$ is the intrinsic growth rate of the resource; and $K$ is its carrying capacity. In the experiment, the following parameters: $r=0.1$ and $K=80$, are used. The renewal rate of resources, as well as how much everyone harvested in each period, were known to participants. In particular, subjects could observe the harvesting choices of others, appearing in a random order on the screen after each round. This meant, however, that they could not track who harvested how much over time. Subjects were also informed about the total extraction and resources in the partner group each period. Individuals are expected to harvest 0.055 of resources in the equilibrium (see eqn. 11 in Appendix A1). On the other hand, the social optimum requires that subjects harvest the renewal rate of resources in the equilibrium $(r R / K)$, thus $2 / 3$ tokens per person. This in turn implies that the socially optimal fraction of harvested resources equals $(2 / 3) / 40=0.02$. Overall, our model predicts the tragedy of the commons, i.e., that group members will harvest above the social optimum of $0.02<$ 0.05 . If a group exhausts the resources, everyone loses their payoff from the third part of the experiment. Regardless of the outcome of the actual experiment, subjects received a show-up fee and an additional reimbursement for each correct answer in the IQ test preceding the experiment (see Appendix 1, C).

\section{Shock treatment}

In the shock treatment, a shock could diminish a fraction of resources $0<\theta_{t}<1$ in each period. Shocks are drawn randomly from the uniform distribution $U(0.5,1.5)$ with a probability of 0.33 . Thus, a group suffered a shock on average every third period. I only considered negative shocks that diminish resources. This is because of the fact that, in the presence of positive events, resource conservation is not necessary to prevent the collapse of a group. Information about whether a shock had destroyed part of the resources was revealed to students after they made their harvesting decisions. I expected that shocks encourage resource conservation. In particular, the fraction of harvested resources $\left(\mathrm{X}^{*} / \mathrm{R}^{*}\right)$ in the linear-symmetric Nash-Markov equilibrium is lower in the shock treatment compared to the baseline solution (see Appendix A1 for derivations, and Antoniadou et al. 2013):

$$
\begin{aligned}
& \left(X^{*} / R^{*}\right)_{\text {baseline }}= \\
& \quad \frac{1-\beta p(1-r)}{2 \beta p}>\left(X^{*} / R^{*}\right)_{\text {shocks }}=\frac{1-\beta p(1-r+r \theta+\theta)}{2 \beta p}
\end{aligned}
$$

where $\beta$ is the discount rate, and $p$ is the probability that a game continues to the next round.

\section{Intergroup sharing treatment}

In the sharing treatment, after harvesting decisions, subjects could decide how many harvests they would like to send to augment the resources of the partner group. Subjects were informed about the level of resources and total harvests in the partner group before the sharing decisions. There are two possible explanations why someone would sacrifice his/her payoff to help outgroup members. First, they may be motivated by altruism or inequality aversion. Second, subjects may share a fraction $c$ of their harvests, anticipating a transfer of resources from the partner group. If participants are "imperfect" conditional cooperators, they would share at least slightly less compared to what they have previously received, $c-\epsilon, 0<\epsilon<c$ (Fischbacher et al. 2001). In this case, intergroup sharing will cease over time. As a result, the option to share should not influence participants' extraction levels at all

The experimental evidence in the next section indicates that many groups established long-lasting resource exchanges, sharing resources with the outgroup until the last round, thus acting as "perfect" conditional cooperators. Let's assume that subjects share fraction $c$ of their harvests with outgroup members. This lowers individual payoffs: $x(1-c)$, in anticipation that outgroup members would reciprocate the donation. The donation would increase the resource by a transfer of $c X$.

Figures 1(a) and (b) illustrate, with numerical examples, the resource dynamics along the socially optimal path of extraction and accumulated payoffs, respectively (see Appendix 1, A2 for derivations, in figures we use the parameter values as in the experiment). Along the socially optimal path, groups maintain resources at half of their carrying capacity $(80 / 2=40)$, while harvesting the renewal rate of resources equal to 2. It becomes apparent from Figure 1(a) that $c=0$, thus the absence of intergroup sharing constitutes the socially optimal strategy. In turn, increasing the value of $c$ reduces accumulated profits. In particular, sharing resources makes subjects incur a payoff loss as participants give up their own harvests to augment the stock 
of resources in the partner group. A donation received in return reduces the regrowth of a group's resource. This is because the regrowth of resources is maximized if resources are equal to half of their carrying capacity, whereas the donation makes resources exceed this level.

Fig. 1. Optimal intergroup cooperation; parameter values are equal to values used in the experiment; initial harvests are equal to 2 in (a) and (b), and to 2.5 in (c) and (d), for beta $=1$.
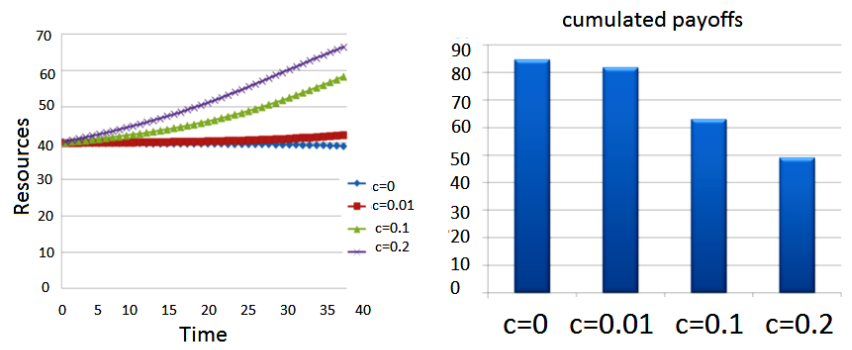

(a) Resources under socially optimal harvests (b) payoffs under socially optimal harvests

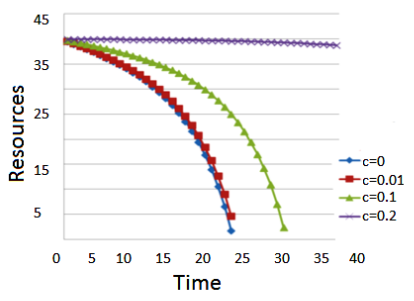

(c) Resources under overharvesting

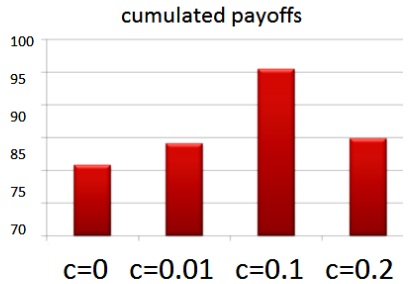

(d) payoffs under overharvesting
If resources are below their socially optimal level, increasing the value of $c$ can prevent resource exhaustion, as well improve individual payoffs (Fig. 1(c) and (d)). In this case, receiving a donation increases not only the resource stock, bringing it closer to the socially optimal level, but also its renewal rate, and thus allows participants to harvest more resources in future rounds. The optimal value of $c$ depends on how far the resource stock is from its socially optimal level. All in all, sharing resources with outgroup members is only beneficial if groups overharvest resources.

\section{Mixed treatment (shocks and sharing)}

I conducted an additional experiment to study the impact of interactions between sharing and shocks (shocks + sharing treatment) on harvesting and the probability of resource exhaustion. In this treatment, subjects learned whether a random shock destroyed a part of their resources or the resources of the partner group, after harvesting and before sharing decisions. The mixed session with shocks and sharing was only conducted in Vienna. As a result, I provide evidence from two empirical studies: (1) using data pooled from Poland and Austria to examine the impacts of shocks and intergroup sharing on harvesting and (2) using data from the Austrian sample alone to examine the impact of shocks on sharing.

\section{RESULTS AND DISCUSSION}

Most groups have significantly diminished resources during the first five periods, supporting the "tragedy of the commons" prediction of Hardin (Hardin 1968). Only one group in the shock treatment succeeded in maintaining resources close to the social optimum over time (see the panels in Appendix 1, B). Figure 2 summarizes the mean resources per treatment in each period. The figure illustrates that mean resources in the shock and sharing treatments are substantially larger compared to the baseline. This effect is statistically significant. Formally, to assess whether the differences in resources per group between treatments are significant, I regressed dummies corresponding to different treatments on harvests, with no constant and error terms clustered at partner group level, using the OLS regression. Subsequently, I tested whether differences in coefficients corresponding to different treatments were significantly different from each other. Because of the remixing of the group after the rounds of training, we cannot use nonparametric tests to examine statistically significant differences between treatments. Table 2(b) summarizes the F-statistics, indicating which differences in mean resources are statistically significant between treatments.

Fig. 2. Mean resources per treatment.

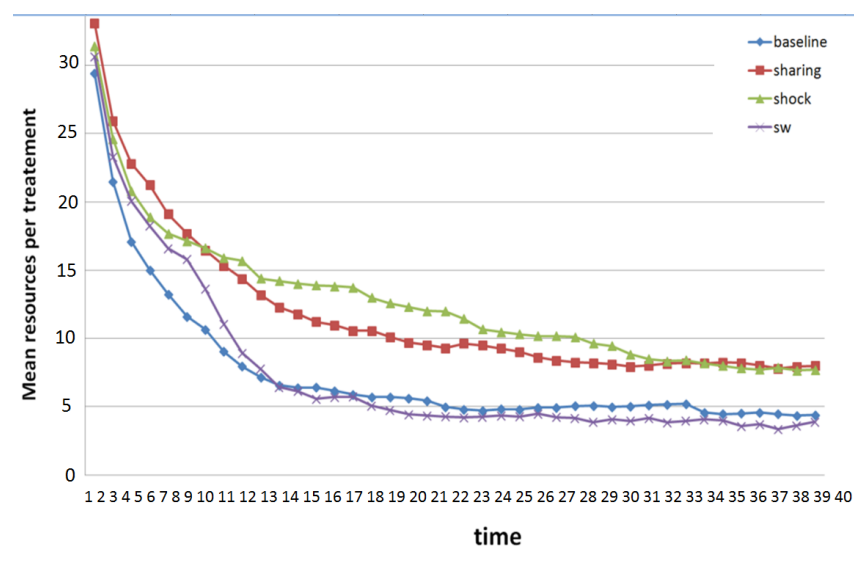

Table 2. Significant differences in the mean fraction of harvested resources between treatments (a). Significant differences in mean resources (before exhaustion) between treatments (b). In tables, I report $\mathrm{F}(1,79)$-statistics.

\begin{tabular}{llll}
\hline \hline & Shocks & Sharing & SW \\
\hline Table 2(a) & & & \\
Baseline & $3.80^{*}$ & 0.36 & $3.29^{*}$ \\
Shocks & & $3.66^{*}$ & $6.15^{* *}$ \\
Sharing & & & 1.98 \\
Table 2(b) & & & \\
Baseline & $5.71^{* *}$ & $4.73^{* *}$ & $2.97^{*}$ \\
Shocks & & 0.10 & 1.09 \\
Sharing & & & 0.53 \\
\hline
\end{tabular}

*** indicates variable significant at 0.01 level, ${ }^{* *}$ at 0.05 , and ${ }^{*}$ at 0.1 level.

The fact that mean resources in the shock treatment exceeded the resources in the baseline treatment can be explained by the shocks encouraging subjects to conserve resources. In favor of this, the mean fraction of harvested resources is significantly lower in the shock treatment compared to the baseline (Table 2a). On the other hand, the greater resources in the sharing treatment compared to the baseline cannot be explained by groups restricting their 
Table 3. The fraction of resources harvested by subjects (standard deviations in parentheses).

\begin{tabular}{|c|c|c|c|c|c|}
\hline & $\begin{array}{c}\text { Model 1 } \\
\text { (data pooled from all } \\
\text { treatments; } \\
\text { bootstrapping } \\
\text { technique used) }\end{array}$ & $\begin{array}{l}\text { Model } 2 \\
\text { (data from the sharing } \\
\text { treatment and from } \\
\text { the shock treatment) }\end{array}$ & $\begin{array}{c}\text { Model } 3 \\
\text { (data from the } \\
\text { sharing, and 'sharing } \\
\text { and shock' treatments) }\end{array}$ & $\begin{array}{c}\text { Model } 4 \\
\text { (data pooled from all } \\
\text { treatments, fixed- } \\
\text { effects model; } \\
\text { bootstrapping } \\
\text { technique used) }\end{array}$ & $\begin{array}{c}\text { Model } 5 \\
\text { (data pooled from all } \\
\text { treatments, with AR(1) } \\
\text { disturbances) }\end{array}$ \\
\hline (Shock/Resource) $_{-1}$ & & $\begin{array}{c}-0.08 * * * \\
(0.01)\end{array}$ & $\begin{array}{c}-0.07 * * * \\
(0.02)\end{array}$ & $\begin{array}{c}-0.08 * * * \\
(0.01)\end{array}$ & \\
\hline$(\text { Shock/Resource })_{-1 \text { partner group }}$ & & $\begin{array}{l}-0.01 \\
(0.01)\end{array}$ & $\begin{array}{l}-0.01 \\
(0.01)\end{array}$ & $\begin{array}{l}-0.01 \\
(0.01)\end{array}$ & \\
\hline Mean fraction of resources in the & 0.03 & 0.05 & 0.02 & & 0.03 \\
\hline rounds of training & $(0.03)$ & $(0.04)$ & $(0.01)$ & & $(0.03)$ \\
\hline Mean harvests by the training group & $\begin{array}{l}-0.003 \\
(0.003)\end{array}$ & $\begin{array}{l}-0.003 \\
(0.004)\end{array}$ & $\begin{array}{c}0.002 \\
(0.003)\end{array}$ & & $\begin{array}{l}-0.002 \\
(0.003)\end{array}$ \\
\hline $\begin{array}{l}\text { Dummy indicating if a trial group } \\
\text { collapsed }\end{array}$ & $\begin{array}{c}-0.01 \\
(0.008)\end{array}$ & $\begin{array}{l}-0.004 \\
(0.005)\end{array}$ & $\begin{array}{r}-0.009 \\
(0.01)\end{array}$ & & $\begin{array}{r}-0.007 \\
(0.01)\end{array}$ \\
\hline Donation to the partner group $_{-1}$ & & $\begin{array}{l}0.004^{*} \\
(0.002)\end{array}$ & $\begin{array}{c}0.004^{* *} \\
(0.002)\end{array}$ & $\begin{array}{l}0.0004 \\
(0.005)\end{array}$ & \\
\hline Donation from the partner dummy $_{-1}$ & & $\begin{array}{l}0.02 * \\
(0.01)\end{array}$ & $\begin{array}{c}0.01 \\
(0.01)\end{array}$ & $\begin{array}{c}0.01 \\
(0.01)\end{array}$ & \\
\hline Mean harvests of others ${ }_{-1}$ & $\begin{array}{l}0.01 * * * \\
(0.0021)\end{array}$ & $\begin{array}{c}0.01 * * * \\
(0.001)\end{array}$ & $\begin{array}{c}0.01 * * * \\
(0.002)\end{array}$ & $\begin{array}{c}0.01 * * * \\
(0.002)\end{array}$ & $\begin{array}{c}0.01 * * * \\
(0.001)\end{array}$ \\
\hline Sharing Treatment & $\begin{array}{c}0.001 \\
(0.005)\end{array}$ & & & & $\begin{array}{c}0.0004 \\
(0.01)\end{array}$ \\
\hline Shock Treatment & $\begin{array}{l}-0.02 * * * \\
(0.01)\end{array}$ & & & & $\begin{array}{c}-0.01 * * * \\
(0.005)\end{array}$ \\
\hline Sharing + Shock Treatment & $\begin{array}{c}0.03 * * * \\
(0.01)\end{array}$ & & & & $\begin{array}{c}0.02 * * * \\
(0.01)\end{array}$ \\
\hline Risk & $\begin{array}{c}0.02 * \\
(0.2)\end{array}$ & $\begin{array}{l}0.01 * \\
(0.01)\end{array}$ & $\begin{array}{c}0.04 \\
(0.05)\end{array}$ & & $\begin{array}{c}0.02^{* *} \\
(0.01)\end{array}$ \\
\hline Female & $\begin{array}{c}-0.01 * * \\
(0.01)\end{array}$ & $\begin{array}{l}-0.001 \\
(0.004)\end{array}$ & $\begin{array}{c}-0.02 * * \\
(0.01)\end{array}$ & & $\begin{array}{l}-0.01 \\
(0.004)\end{array}$ \\
\hline Total IQ & $\begin{array}{c}-0.004 * * \\
(0.003)\end{array}$ & $\begin{array}{l}-0.002 \\
(0.001)\end{array}$ & $\begin{array}{l}-0.01 \\
(0.01)\end{array}$ & & $\begin{array}{r}-0.003^{*} \\
(0.002)\end{array}$ \\
\hline Trust & $\begin{array}{l}-0.01 \\
(0.01)\end{array}$ & $\begin{array}{l}0.004 \\
(0.01)\end{array}$ & $\begin{array}{l}0.001 \\
(0.02)\end{array}$ & & $\begin{array}{l}-0.01 \\
(0.01)\end{array}$ \\
\hline Divide & $\begin{array}{l}-0.01 \\
(0.01)\end{array}$ & $\begin{array}{l}-0.01 \\
(0.01)\end{array}$ & $\begin{array}{l}-0.002 \\
(0.02)\end{array}$ & & $\begin{array}{l}-0.01 \\
(0.01)\end{array}$ \\
\hline Poland & $\begin{array}{l}0.005 \\
(0.01)\end{array}$ & $\begin{array}{c}0.004 \\
(0.004)\end{array}$ & $\begin{array}{r}-0.001 \\
(0.02)\end{array}$ & & $\begin{array}{c}0.004 \\
(0.004)\end{array}$ \\
\hline Constant & $\begin{array}{l}0.06^{*} \\
(0.02)\end{array}$ & $\begin{array}{l}0.04 * \\
(0.02)\end{array}$ & $\begin{array}{c}0.04 * * \\
(0.02)\end{array}$ & $\begin{array}{c}0.03 * * * \\
(0.002)\end{array}$ & $\begin{array}{c}0.06 * * * \\
(0.02)\end{array}$ \\
\hline $\mathrm{N}$ obs & 6990 & 4098 & 2658 & 6990 & 6990 \\
\hline $\mathrm{N}$ groups & 240 & 144 & 96 & 240 & 240 \\
\hline R2 within & 0.11 & 0.13 & 0.10 & 0.11 & 0.11 \\
\hline between & 0.47 & 0.61 & 0.56 & 0.47 & 0.48 \\
\hline overall & 0.13 & 0.15 & 0.13 & 0.12 & 0.13 \\
\hline Wald statist & $W(13)=1277.4$ & $\mathrm{~W}(7)=$ & $W(11)=$. & $W(5)=534.7$ & $W(13)=741.47$ \\
\hline
\end{tabular}

*** indicates variables significant at the $1 \%$ level, $* *$ at the $5 \%$ level, and $*$ at the $10 \%$ level

harvests. In fact, I provide evidence that the receipt of a transfer of resources from the outgroup has no effect on harvesting. Instead, the difference in resources between sharing and baseline treatments is due to intergroup transfers between partner groups, augmenting their resources. In particular, I find that intergroup sharing is frequent and reciprocal between groups. Groups that established reciprocal exchanges were successful in preventing resource exhaustion, but only in the absence of shocks. The probability of resource exhaustion was 0 in the sample of students in Austria, who shared resources with the outgroup more frequently than Polish students (Table 1). In the treatment with combined shocks and sharing, groups harvested a significantly larger fraction of resources compared to the baseline and shock treatments (Table 2a). The results suggest that intergroup sharing undermines the positive impact of shocks on resource conservation.

Result 1. Shocks that destroy part of the resources promote resource conservation. The positive impact of shocks on resource conservation disappears in the presence of intergroup sharing. A combination of shocks and sharing makes subjects overharvest resources

To examine the factors conducive to overharvesting resources, I conducted panel regressions with the dependent variables: a fraction of the harvested resources by an individual at time $t$. Table 3 compares the results from the random-effects models (Model 1-3) and the fixed-effects model (Model 4) with results 
from the model with $\mathrm{AR}(1)$ disturbances (Model 5). The Hausman test indicates that the fixed-effects model is preferable over random-effect regressions $(\mathrm{Chi} 2(5)=75.94)$. However, the former model does not allow the study of the impact of timeinvariant variables, so I report the results from random and fixedeffect models. I clustered errors at the session level in Models 1-4. In Models 1 and 4, I used a bootstrapping technique to compute and control for dependencies of the error terms. In Models 2 and 3 , the number of observations was insufficient to bootstrap the errors because only the subset of data in these regressions was used, i.e., from the sharing and shock treatments in Model 2, and from the sharing, and sharing and shock treatments in Model 3. In Model 5, I introduced AR(1) disturbances to control for serial correlation. In particular, the Wooldridge test indicated that the data suffer from this problem $(\mathrm{F}(1,239)=32.30)$. In all regressions, I only considered observations before partner groups exhausted their resources. The results in Table 3 show that the findings are robust to different regression techniques.

To control for possible dependencies in the behavior of subjects created because of the reshuffling of groups after the rounds of training, I added the following independent variables: (1) the dummy indicating whether a group to which a subject belonged to during the trial exhausted resources; (2) the mean harvests by a training group over 10 periods; and (3) the mean fraction of resources harvested in the training rounds by each subject. However, these variables turned out to be insignificant in explaining the behavior of participants in the actual experiment.

In addition, I included dummies corresponding to different treatments in the regressions; the dummy taking the value of 1 if a student came from a Polish sample and 0 if he/she took part in an experiment conducted in Austria; the lagged values of fractions of resources destroyed by a shock in the group and in the partner group; a dummy indicating whether a group received resources from its partner group in the past period; and harvests donated by subjects to the outgroup. As control variables, I also included the outcomes of the trust and dictator game preceding the experiment. In particular, the variables "trust" and "divide" measured the fraction of $€ 1$ that subjects were willing to give to another person in the dictator and trust game, respectively. Risk indicates the fraction of $€ 1$ that subjects were willing to invest in the risky project, and total IQ measures the number of corrected answers in the cognitive test (see Appendix 1, C).

Results indicate that subjects harvest significantly less resources in the presence of shocks than in their absence. In favor of this, the lagged value of shocks has a statistically significant and negative impact on the fraction of harvested resources in Models $2-4$, whereas the dummy corresponding to the shock treatment has a statistically significant and negative impact on harvesting in Models 1 and 5. Results from the preceding studies suggest that uncertainty about resources is likely to promote overharvesting in the experimental setting, when the availability of resources in the future is independent of current decisions (Rapoport et al. 1992). In our experiment, the fact that resources are renewable aligns the fate of group members. As a result, shocks create an additional risk of loss, not only of current, but also future profits. Results showing that shocks promote resource conservation are similar to the findings of Schill et al. (2015) and Milinski et al. (2008, 2010). In the Schill et al. (2015) experiment, subjects harvest from renewable common-pool resources, like in my experiment. The authors show that communication is key to overcoming the commons dilemmas. On the other hand, in my experiment, resource uncertainty can cause subjects to conserve resources even in the absence of communication. In turn, in the experiment by Milinski et al. (2008), groups of players were asked to invest money into a public good to avoid dangerous climate change. The authors found that the chances of achieving such a target increase the higher the probability that individuals will lose all of their investments, if the target level of contributions is not reached over time.

My results indicate that a combination of sharing and shocks causes subjects to overharvest resources. In favor of this, the dummy corresponding to the sharing and shock treatment had a positive and statistically significant impact on individual harvests in Models 1 and 5. This surprising result can be explained by the fact that intergroup donations are significantly higher in the presence of shocks than in their absence (Result 5). It seems that high donations from the outgroup in the presence of shocks undermine participants' motivation to conserve resources. In fact, $25 \%$ of participants strongly agreed in the postexperiment questionnaire with the statement that they believed, before the experiment, that the partner group would share resources with them in case they lost some resources because of a shock. This suggests that subjects may perceive sharing as some type of insurance against shocks, which in turn can lead to moral hazard (O'Hare at al. 2015). As a result, group members do not reduce their extractions, which is necessary to prevent resource collapse in the presence of shocks, in the expectation that donations from the outgroup would compensate for their risky behavior.

The mean harvests of the other group members turn out to have a significant and positive impact on individual harvests. This provides a possible explanation behind the depletion of resources; subjects adjust their extraction levels to the harvests of other group members so as not to fall behind them, which leads to a vicious circle of the increasing exploitation of natural resources and their diminishing stocks. Adjusting one's own harvests to the extraction levels of other peers can be indicative of inequity aversion. Falk et al. (2002) showed that a simple model of fairness can explain many stylized facts from common-pool resource experiments. Finally, I found that risk seeking increases the fraction of harvested resources, whereas total IQ encourages resource conservation.

Result 2. Receiving a donation of resources from the outgroup has no significant effect on individual harvests in the absence of shocks. However, subjects who donated resources harvest a significantly larger fraction of resources in the following round. This suggests that participants may try to compensate for the loss of donated harvests by extracting more resources.

The results in Table 3 indicate that receiving resources from the partner group has a positive yet insignificant effect on the fraction of harvested resources. Interestingly, donating resources to the outgroup has a significant and positive impact on individual harvests in most regressions (Models 2 and 3). Thus, it seems that subjects try to compensate giving away their harvests to the outgroup by extracting more resources in the rounds following donations. In turn, this suggests that intergroup cooperation may undermine intra-group cooperation. 
Sharing resources with the outgroup turns out to maximize individual payoffs, which supports my theoretical predictions (Fig. 1). The results in Table 1 indicate that the payoffs are the largest in the sharing treatment in both Polish and Austrian samples. The differences in payoffs between sharing and all other treatments in both samples are statistically significant, with the exception of the sharing and baseline treatments in Poland $(\mathrm{F}(1,23)=2.19)$.

\section{Result 3. Many groups established long-lasting resource-sharing arrangements. Establishing a reciprocal donating relationship with the outgroup reduces the probability of resource exhaustion in the absence of shocks.}

I found that many groups established long-lasting resource-sharing arrangements in which partner groups shared resources with each other frequently until the end of the experiment. I observed considerable differences in the behavior of students from Warsaw and Vienna. In the sharing treatment, the frequency of donations to the outgroup was $26 \%$ in Poland, whereas in Austria, subjects shared resources with the outgroup in $52 \%$ of the rounds during which both groups existed (i.e., before resource collapse). The difference in the frequency of sharing is statistically significant between samples $(\mathrm{F}(1,11)=8.65,<0.001)$. In turn, I found no statistically significant difference in the mean donations between countries; on average Polish subjects shared 0.68( \pm 0.13$)$ tokens with the outgroup, whereas Austrian subjects shared 0.73( \pm 0.18$)$ of resources $(\mathrm{F}(1,11)=0.05)$.

In the sample of students from the University of Vienna, reciprocal exchanges lasted until the very end, preventing resource exhaustion in all groups in the sharing treatment. In the sample of students from the University of Warsaw, exchanges typically ceased after the initial period. As a result, in the sharing treatment the probability of survival was $100 \%$ in the sample of students from Vienna, and $70 \%$ in the sample of students from Warsaw. This discrepancy can be explained by the fact that students from Vienna were twice as likely as Polish students to believe that outgroup members would share resources with them. In particular, $58 \%$ of subjects from Vienna agreed (or strongly agreed) that a partner group would share some resources with them in case their group overharvested resources, according to the postexperiment questionnaire. Only $29 \%$ of subjects in the sample of students at Warsaw University agreed with this statement. However, as subjects were interviewed after the experiment, their experience might have influenced their answers with respect to their belief that the other group would share resources. On the other hand, these findings are consistent with the empirical evidence that culture and socioeconomic background can affect trust toward strangers and beliefs about the fairness and helpfulness of others (Gächter et al. 2004). Halman (2001) reported a significant difference in trust between Poland and Austrian citizens, using data from the European Value Survey. In the European Value Survey, 33.9\% of respondents in Austria agreed with the statement "most people can be trusted" compared to $18.9 \%$ of Polish citizens. In turn, $66.1 \%$ of people in Austria agreed that "you can't be too careful in dealing with people" compared to $81.1 \%$ of respondents in Poland.

Results 4. The possible explanations of the high frequency of intergroup sharing in my sample are inequality aversion and reciprocity.

What are the other reasons why individuals would share resources with outgroup members? Possible explanations include reciprocity, inequality aversion, and altruism. To examine which of these explanations are more likely, I conducted mixed-level logit regressions with the dependent variable having a value of one if a subject shared his/her harvests with outgroup members and zero otherwise (Table 4). I clustered errors within groups, then within the partner groups, and finally within sessions in the analysis. I included the following as independent variables: the difference between own resources and resources in the partner group if the difference is positive; the additional variable capturing the absolute difference in resources between groups if the difference is negative, i.e., if the group has fewer resources than the outgroup at time $t$; the fraction of harvested resources before sharing decisions; lagged values of shocks in the group and the partner groups; the lagged values of resources shared with the outgroup by other group members and the donation received from the outgroup; and the interaction term with a value of one if a group received a donation and simultaneously suffered a shock in the previous round. I included donations from other group members as a proxy of subjects' willingness to share harvests with the partner group in the past. Figure A1.2 in Appendix 1 illustrates that the more often groups share resources, the higher the percentage of collective contributions, i.e. when more than one group member shared his/her harvests with the outgroup. Finally, I controlled for outcomes of the pre-experiment questionnaire as in Table 3, but additionally included the following: the expectation of intergroup help from the postexperimental questionnaire; the proportion of money returned in the trust game (trustworthiness); and the variable "dummy trust A," which equals one if a person shared nothing in the trust game, whereas "dummy trust B" equals one if a person received nothing in the trust game and zero otherwise (see Appendix 1, C).

The results suggest that inequality aversion can explain intergroup sharing. The difference between own resources and resources in the partner group had a positive and statistically significant impact on the probability of sharing in Models 1-3. This indicates that members of groups, more affluent in resources than partner groups, are more likely to donate their harvests to the outgroup, perhaps to offset the inequality of resources between groups. In turn, the absolute negative difference in resources between groups has a negative impact on the probability of sharing. This implies that if a group has less resources than its partner, it is also less likely to donate resources to the outgroup, supporting the inequality aversion hypothesis.

In addition, I found that subjects were more likely to share harvests with the outgroup in case they harvested more resources for themselves. In particular, a fraction of harvested resources turned out to have a significant and positive impact on the probability of sharing in all regressions. However, the evidence in Table 3 indicates that subjects who shared resources also harvested a larger fraction of resources for themselves. This questions altruism as an explanation for intergroup help. Instead, the results suggest that subjects behaved as conditional cooperators. In favor of this, the lagged value of donations from the partner group had a statistically significant and positive impact on the probability of sharing in all regressions. In addition, past donations made to the partner group by other group members had a statistically significant and positive impact on intergroup sharing in Models 1 and 3 . In fact, in $71 \%$ of cases, the sharing of resources with the outgroup members was preceded by receiving a transfer of resources from the outgroup. 
Table 4. Results from the mixed-level logit panel regressions with the depend variable taking 1 if a subject shared some of his/her harvest with outgroup members and 0 otherwise. The sample includes only data if case resources in the group and in the partner group are larger than 1. Data at the individual level are nested within groups, and then within partner groups, and finally within sessions in the analysis. Standard deviations in parentheses.

\begin{tabular}{|c|c|c|c|c|}
\hline & $\begin{array}{c}\text { Model } 1 \\
\text { (data from the sharing } \\
\text { treatment, from Austria } \\
\text { and Poland) }\end{array}$ & $\begin{array}{l}\text { Model } 2 \\
\text { (data from the sharing } \\
\text { treatment, from Austria } \\
\text { and Poland) }\end{array}$ & $\begin{array}{l}\text { Model } 3 \\
\text { (data from the sharing } \\
\text { treatment, from Austria } \\
\text { and Poland) }\end{array}$ & $\begin{array}{l}\text { Model } 4 \\
\text { (data from sharing and } \\
\text { 'sharing and shocks' } \\
\text { treatments; only Austrian } \\
\text { sample) }\end{array}$ \\
\hline A fraction of harvested resources & $\begin{array}{c}5.03^{* * *} \\
(1.15)\end{array}$ & $\begin{array}{c}4.88^{* * *} \\
(1.11)\end{array}$ & $\begin{array}{c}4.51 \text { *** } \\
(1.14)\end{array}$ & $\begin{array}{c}7.12 * * * \\
(1.22)\end{array}$ \\
\hline Positive difference in resources & $\begin{array}{l}0.02^{*} \\
(0.01)\end{array}$ & $\begin{array}{l}0.02 * \\
(0.01)\end{array}$ & $\begin{array}{l}0.02^{*} \\
(0.01)\end{array}$ & $\begin{array}{c}0.02 \\
(0.02)\end{array}$ \\
\hline Absolute negative difference in resources & $\begin{array}{l}-0.02^{*} \\
(0.01)\end{array}$ & $\begin{array}{l}-0.02 \\
(0.01)\end{array}$ & $\begin{array}{l}-0.03^{*} \\
(0.02)\end{array}$ & $\begin{array}{l}-0.04^{*} \\
(0.02)\end{array}$ \\
\hline Shock received & & & & $\begin{array}{l}-0.34 \\
(0.49)\end{array}$ \\
\hline Shock received by the partner group & & & & $\begin{array}{l}-0.19 \\
(0.29)\end{array}$ \\
\hline $\begin{array}{l}\text { Donation to the outgroup by the others } \\
\text { in a group }\end{array}$ & $\begin{array}{l}0.16^{*} \\
(0.10)\end{array}$ & $\begin{array}{c}0.11 \\
(0.10)\end{array}$ & $\begin{array}{l}0.18^{*} \\
(0.10)\end{array}$ & $\begin{array}{l}-0.06 \\
(0.10)\end{array}$ \\
\hline Resources received from the outgroup -1 & $\begin{array}{c}0.44 * * * \\
(0.08)\end{array}$ & $\begin{array}{c}0.42 * * * \\
(0.08)\end{array}$ & $\begin{array}{c}0.43 * * * \\
(0.08)\end{array}$ & $\begin{array}{c}0.37 * * * \\
(0.08)\end{array}$ \\
\hline Interaction Shocks and Donation $_{-1}$ & & & & $\begin{array}{c}0.31 \\
(0.52)\end{array}$ \\
\hline Risk & $\begin{array}{l}-0.46 \\
(0.73)\end{array}$ & & $\begin{array}{l}-0.62 \\
(0.52)\end{array}$ & $\begin{array}{c}-0.46 \\
(0.52)\end{array}$ \\
\hline Total IQ & $\begin{array}{c}0.34 * * * \\
(0.08)\end{array}$ & & $\begin{array}{c}0.39 * * * \\
(0.08)\end{array}$ & $\begin{array}{c}-0.23 * * * \\
(0.08)\end{array}$ \\
\hline Trust & $\begin{array}{l}-1.14 \\
(0.73)\end{array}$ & & & $\begin{array}{l}-0.91 \\
(0.57)\end{array}$ \\
\hline Divide & $\begin{array}{l}-0.19 \\
(0.68)\end{array}$ & & & $\begin{array}{c}-0.63 \\
(0.59)\end{array}$ \\
\hline Female & $\begin{array}{l}-0.21 \\
(0.21)\end{array}$ & & $\begin{array}{l}-0.14 \\
(0.17)\end{array}$ & $\begin{array}{c}0.64 * * * \\
(0.22)\end{array}$ \\
\hline Expectation of intergroup help & $\begin{array}{c}0.16^{* *} \\
(0.07)\end{array}$ & & & $\begin{array}{c}0.33 * * * \\
(0.09)\end{array}$ \\
\hline Dummy trust A & $\begin{array}{c}-1.27 * * * \\
(0.31)\end{array}$ & & $\begin{array}{c}-0.68^{* *} \\
(0.31)\end{array}$ & $\begin{array}{c}-1.63^{* * *} \\
(0.41)\end{array}$ \\
\hline Dummy trust B & $\begin{array}{c}-0.67 * * * \\
(0.24)\end{array}$ & & $\begin{array}{c}-0.90^{* * * *} \\
(0.26)\end{array}$ & $\begin{array}{l}-0.53^{*} \\
(0.31)\end{array}$ \\
\hline Trustworthiness & & & $\begin{array}{c}-1.16^{* * * *} \\
(0.34)\end{array}$ & \\
\hline Poland & & $\begin{array}{c}-1.60^{* * *} \\
(0.59)\end{array}$ & & \\
\hline Constant & $\begin{array}{c}-2.52 * * * \\
(0.51)\end{array}$ & $\begin{array}{c}-1.81 * * * \\
(0.46)\end{array}$ & $\begin{array}{c}-2.48 * * * \\
(0.49)\end{array}$ & $\begin{array}{c}-1.63 * * * \\
(0.48)\end{array}$ \\
\hline $\begin{array}{l}\mathrm{N} \text { obs } \\
\text { groups }\end{array}$ & $\begin{array}{c}2122 \\
24\end{array}$ & $\begin{array}{c}2122 \\
24\end{array}$ & $\begin{array}{c}2122 \\
24\end{array}$ & $\begin{array}{c}1506 \\
16\end{array}$ \\
\hline Wald chi2 2 & $\mathrm{~W}(13)=119.05$ & $\begin{array}{c}24 \\
W(6)=71.28\end{array}$ & $\begin{array}{c}24 \\
W(11)=112.04\end{array}$ & $\begin{array}{c}16 \\
W(15)=81.60\end{array}$ \\
\hline
\end{tabular}

*** indicates variables significant at the $1 \%$ level, ${ }^{* *}$ at the $5 \%$ level, and * at the $10 \%$ level

The dummy indicating whether a subject came from Poland had a negative impact on the probability of sharing. Surprisingly, the trust variable had a negative impact on the probability of sharing. It was, however, statistically insignificant in explaining intergroup sharing (Model 1 and 4). Taking a closer look at the data from the trust game preceding the experiment, I found very high levels of zero responses, in which subjects shared nothing in the trust game. This contrasts with findings from the meta-analysis of results from 162 trust games world-wide conducted by Johnson and Mislin (2011). The authors found that results from the trust game are typically normally distributed, quoting $62 \%$ as the mean contribution in Austria. In my sample, subjects shared $34 \%$ of $€ 1$ with another person in the Austrian sample (median $28 \%$ ) and $33 \%$ (median $40 \%$ ) in Poland. The difference between my results and the preceding studies can be motivated by the fact that participants could not win substantial money in my experiment because the trust game was conducted as a part of the preexperimental questionnaire. I controlled for an unusually high frequency of zero responses in the analysis by introducing dummies capturing whether a person sent or received zeros in the trust game. The trust game was played between two randomly matched participants, who simultaneously decided how much of 
$€ 1$ they would like to share with another person. Both variables turned out to have a negative impact on the probability of sharing. All in all, the experience of individuals in the trust game might have biased participants' expectations over what to expect from another group. Moreover, the negative impact of trust on intergroup sharing suggests that other factors exist that drive the differences in behavior of Polish and Austrian participants, such as rules or social norms.

Result 5. Shocks to resources in the previous round are insignificant in explaining the probability of sharing.

However, the mean donation to the outgroup is substantially larger in the treatment combining sharing and shocks compared to the sharing treatment alone. Thus, intergroup sharing can be seen as a means of coping with environmental risk. However, it turns out to be ineffective in mitigating climate change impacts because intergroup cooperation crowds out the intrinsic motivations of subjects to conserve resources under resource uncertainty.

Finally, I examined the impact of resource uncertainty on the probability of sharing. Because the mixed treatment with sharing and shocks was only performed in Austria, I only compared the frequency of intergroup sharing in the Austrian sample. I found that there was no statistically significant difference between the frequency of sharing in the presence or absence of shocks. In the absence of shocks, the frequency of sharing (i.e., a percentage of rounds in which a group shared resources with its partner during the period that both groups existed) was $52 \%( \pm 19 \%)$; whereas in the presence of shocks it was $49 \%( \pm 16 \%)$ in the Austrian sample. Moreover, the evidence in Table 4 (Model 4) indicates that neither past shocks, which destroyed part of one's own resources, nor shocks to resources of the partner group, have a statistically significant impact on the probability of sharing. On the other hand, I found statistically significant differences in the mean donations between treatments. The mean donation is $1.23( \pm 0.27)$ in the presence of shocks, whereas in their absence it is equal to half of this value $0.67( \pm 0.13)$. The difference was statistically significant $(F(1,7)=3.37)$. On average, 0.88 resources $( \pm 0.27)$ were lost because of the shock. Thus, donations from the outgroup were more than enough to compensate for the loss of resources because of shocks. These results are in line with the findings from Cherry et al. (2015). The authors showed that individuals are willing to compensate losses to other group members in the presence of idiosyncratic risk. However, in my experiment, this was insufficient to prevent resource exhaustion in most groups because generous donations encouraged overharvesting.

\section{CONCLUSIONS}

I have presented an experimental design that explores the role of intergroup cooperation in CPR dilemmas. In the experiment, subjects were asked to harvest resources from the common pool of the renewable resource. Subsequently, groups were matched in pairs, which I referred to as partner groups. Subjects could observe the harvesting decisions of members of their own group as well as members of the partner group. In this context, I examined how harvesting from the common pool of resources was affected (1) by random shocks, which could diminish a part of resources, and (2) by intergroup cooperation. My results support the hypothesis that the scarcity of a vital resource coupled with an uncertain danger of its sudden depletion encourages resource conservation. This can be explained by the fact that shocks to resources decrease the probability that the game will continue to the next round. Only by conserving resources could subjects prevent resource exhaustion in the presence of shocks.

Under which conditions would a group of people behave altruistically toward outgroup members? In the sharing treatment, after harvesting decisions, subjects could give up some of their harvests to augment the resource stock of the partner group. Intergroup transfers of resources can be interpreted as subjects donating their own payoffs to support improvements in the resource productivity of the partner group. Most economic models, based on the assumption of rational and selfish agents, rule out gift exchanges or reciprocity in the equilibrium. However, in this experiment I found that the majority of groups established reciprocal exchanges with outgroup members that lasted for many periods. The possible explanations of the high frequency of intergroup sharing in my sample are inequality aversion and reciprocity. These reciprocal exchanges turned out to be successful in preventing a resource collapse in the absence of shocks. However, the data I present show the dark side of intergroup sharing. Subjects who shared resources with the outgroup, harvested more for themselves following the donation. Moreover, under uncertainty, a combination of shocks and sharing made subjects overharvest resources. These findings carry important implications for the governance of commons under resource uncertainty. Establishing sharing arrangements between groups can help them prevent resource exhaustion in the absence of shocks. However, in the event of uncertainty, intergroup cooperation may backfire.

Responses to this article can be read online at: http://www.ecologyandsociety.org/issues/responses. $\mathrm{php} / 9681$

\section{Acknowledgments:}

I would like to thank Marco Janssen, Rupert Sausgruber, Sabina Torunczyk-Ruiz, and James Tremewan for their helpful comments and suggestions. Pablo Torija and Marta Dyrkacz provided technical assistance. The research was supported by grant National Science Center UMO-2013/08/S/HS4/00254.

\section{LITERATURE CITED}

Abbink, R., J. Brandts, B. Herrmann, and H. Orzen. 2010. Intergroup conflict and intra-group punishment in an experimental contest game. American Economic Review 100:420-447. http://dx.doi.org/10.1257/aer.100.1.420

Aflaki, S. 2013. The effect of environmental uncertainty on the tragedy of commons. Games and Economic Behavior 82:240-253. http://dx.doi.org/10.1016/j.geb.2013.07.011

Antoniadou, E., C. Koulovatianos, and L. J. Mirman. 2013. Strategic exploitation of a common-property resource under uncertainty. Journal of Environmental Economics and Management 65:28-39. http://dx.doi.org/10.1016/j.jeem.2012.05.005

Ashton, P. J. 2002. Avoiding conflicts over Africa's water resources. Ambio 31:236-242. http://dx.doi.org/10.1579/0044-7447-31.3.236 
Biel, A., and T. Gärling. 1995. The role of uncertainty in resource dilemmas. Journal of Environmental Psychology 15:221-233. http://dx.doi.org/10.1016/0272-4944(95)90005-5

Blanco, E., T. Haller, and J. M. Walker. 2017. Externalities in appropriation: responses to probabilistic losses. Experimental Economics :1-16. https://doi.org/10.1007/s10683-017-9511-x

Blanco, E., M. C. Lopez, and J. M. Walker. 2016. The opportunity cost of conservation with deterministic and probabilistic externalities. Environmental and Resource Economics 64:255-273. http://dx.doi.org/10.1007/s10640-014-9868-7

Bornstein, G. 2003. Intergroup conflict, individual, group and collective interest. Personality and Social Psychology Review 7:129-145. http://dx.doi.org/10.1207/S15327957PSPR0702 129-145

Bornstein, G., and I. Yaniv. 1998. Individual and group behavior in the ultimatum game: are groups more rational players? Experimental Economics 1:101-108. http://dx.doi.org/10.1023/ A:1009914001822

Botelho, A., A. Dinar, L. M. C. Pinto, and A. Rapoport. 2014. Time and uncertainty in resource dilemmas: equilibrium solutions and experimental results. Experimental Economics 17:649-672. http://dx.doi.org/10.1007/s10683-013-9388-2

Budescu, D. V., A. Rapoport, and R. Suleiman. 1992. Simultaneous vs. sequential request in resource dilemmas with incomplete information. Acta Psychologica 80:297-310. http://dx. doi.org/10.1016/0001-6918(92)90052-F

Budescu, D. V., A. Rapoport, and R. Suleiman. 1995. Common pool resource dilemmas under uncertainty: qualitative tests of equilibrium solutions. Games and Economic Behavior 10:171-201. http://dx.doi.org/10.1006/game.1995.1029

Cherry, T. L., E. L. Howe, and J. J. Murphy. 2015. Sharing as risk pooling in a social dilemma experiment. Ecology and Society 20 (1):68. http://dx.doi.org/10.5751/ES-07390-200168

Copeland, B. R., and M. S. Taylor. 2009. Trade, tragedy, and the commons. American Economic Review 99:725-749. http://dx.doi. org/10.1257/aer.99.3.725

Dixit, A. K., S. A. Levin, and D. I. Rubenstein. 2013. Reciprocal insurance among Kenyan pastoralists. Theoretical Ecology 6:173-187. http://dx.doi.org/10.1007/s12080-012-0169-x

Downing, A. S., E. Van Nes, J. Balirwa, J. Beuving, P. Bwathondi, L. J. Chapman, I. J. M. Cornelissen, I. G. Cowx, K. Goudswaard, R. E. Hecky, J. H. Janse, A. Janssen, L. Kaufman, M. A. KisheMachumu, J. Kolding, W. Ligtvoet, D. Mbabazi, M. Medard, O. C. Mkumbo, E. Mlaponi, A. T. Munyaho, L. A. J. Nagelkerke, R. Ogutu-Ohwayo, W. O. Ojwang, H. K. Peter, D. Schindler, O. Seehausen, D. Sharpe, G. M. Silsbe, L. Sitoki, R. Tumwebaze, D. Tweddle, K. E. Van de Wolfshaar, H. Van Dijk, E. Van Donk, J. C. Van Rijssel, P. A. M. Van Zwieten, J. H. Wanink, F. Witte, and W. M. Mooij. 2014. Coupled human and natural system dynamics as key to the sustainability of Lake Victoria's ecosystem services. Ecology and Society 19(4):31. http://dx.doi.org/10.5751/ ES-06965-190431

Ember, C. R., and M. Ember. 1992. Resource unpredictability, mistrust, and war: a cross-cultural study. Journal of Conflict Resolution 36:242-262. http://dx.doi.org/10.1177/0022002792036002002
Falk, A., E. Fehr, and U. Fischbacher. 2002. Appropriating the commons - a theoretical explanation. Pages 157-192 in T. Dietz, N. Dolsak, E. Ostrom, P. Stern, S. Stonich, and E. Weber, editors. The drama of the commons. National Academy, Washington, D. C., USA.

Fehr, E., and A. Falk. 1999. Wage rigidity in a competitive incomplete contract market. Journal of Political Economy 107:106-134. http://dx.doi.org/10.1086/250052

Fehr, E., E. Kirchler, A. Weichbold, and S. Gächter. 1998a. When social norms overpower competition: gift exchange in experimental labor markets. Journal of Labor Economics 16:324-351. http://dx.doi.org/10.1086/209891

Fehr, E., G. Kirchsteiger, and A. Riedl. 1993. Does fairness prevent market clearing? An experimental investigation. Quarterly Journal of Economics 108:437-459. http://dx.doi. org/10.2307/2118338

Fehr, E., G. Kirchsteiger, and A. Riedl. 1998b. Gift exchange and reciprocity in competitive experimental markets. European Economic Review 42:1-34. http://dx.doi.org/10.1016/S0014-2921 (96)00051-7

Fischbacher, U. 2007. Z-Tree: Zurich toolbox for ready-made economic experiments. Experimental Economics 10:171-178. http://dx.doi.org/10.1007/s10683-006-9159-4

Fischbacher, U., S. Gächter, and E. Fehr. 2001. Are people conditionally cooperative? Evidence from a public good experiment. Economic Letters 71:397-404. https://doi.org/10.1016/ $\underline{\text { S0165-1765(01)00394-9 }}$

Gächter, S., B. Herrmann, and C. Thöni. 2004. Trust, voluntary cooperation, and socio economic backgrounds: survey and experimental evidence. Journal of Economic Behavior and Organization 55:505-531. http://dx.doi.org/10.1016/j.jebo.2003.11.006

Halman, L. 2001. The European values study: a third wave: source book of the 1999/2000 European Values Study surveys. Tilburg EVS, WORC, Tilburg University, Tilburg, The Netherlands.

Hardin, G. 1968. The tragedy of commons. Science 162:1243-1248. http://dx.doi.org/10.1126/science.162.3859.1243

Hine, D. W., and R. Gifford. 1996. Individual restraint and group efficiency in commons dilemmas: the effects of two types of environmental uncertainty. Journal of Applied Social Psychology 26:993-1009. http://dx.doi.org/10.1111/j.1559-1816.1996.tb01121. $\underline{x}$

Intergovernmental Panel on Climate Change (IPCC). 2007. IPCC Fourth assessment report: climate change 2007. Intergovernmental Panel on Climate Change, Geneva, Switzerland. [online] URL: https://www.ipcc.ch/publications and data/publications and data reports.shtml\#1

Janssen, M. A. 2010. Introducing ecological dynamics into common-pool resource experiments. Ecology and Society 15(2):7. http://dx.doi.org/10.5751/ES-03296-150207

Janssen, M. A., R. Holahan, A. Lee, and E. Ostrom. 2011. Lab experiments for the study of social-ecological systems. Science 328:613-617. http://dx.doi.org/10.1126/science.1183532 
Johnsen, D. B. 2009. Salmon, science, and reciprocity on the northwest coast. Ecological Society 14(2):43. http://dx.doi. org/10.5751/ES-03107-140243

Johnson, N. D., and A. A. Mislin. 2011. Trust games: a metaanalysis. Journal of Economic Psychology 32:865-889. http://dx. doi.org/10.1016/j.joep.2011.05.007

Kaya, O., I. Kaya, and L. Gunter. 2013. Foreign aid and the quest for poverty reduction: is aid to agriculture effective? Journal of Agricultural Economics 64:583-596. http://dx.doi. org/10.1111/1477-9552.12023

Kimbrough, E. O., and B. J. Wilson. 2013. Insiders, outsiders, and the adaptability of informal rules to ecological shocks. Ecological Economics 90:29-40. http://dx.doi.org/10.1016/j.ecolecon.2013.02.008

Kocher, M. G., and M. Sutter. 2007. Individuals versus group behavior and the role of the decision making procedure in giftexchange experiments. Empirica 34:63-88. http://dx.doi. org/10.1007/s10663-006-9026-8

McAllister, R. R. J., I. J. Gordon, M. A. Janssen, and N. Abel. 2006. Pastoralists' responses to variation of rangeland resources in time and space. Ecological Applications 16:572-583. http://dx. doi.org/10.1890/1051-0761(2006)016[0572:PRTVOR]2.0.CO;2

Milinski, M., T. Röhl, and J. Marotzke. 2010. Cooperative interaction of rich and poor can be catalyzed by intermediate climate targets. Climatic Change 109:807-814. http://dx.doi. org/10.1007/s10584-011-0319-y

Milinski, M., R. D. Sommerfeld, H.-J., Krambeck, F. A. Reed, and J. Marotzke. 2008. The collective-risk social dilemma and the prevention of simulated dangerous climate change. Proceedings of the National Academy of Sciences 105:2291-2294. http://dx.doi. org/10.1073/pnas.0709546105

Mwiturubani, D. A. 2010. Climate change and access to natural resources. Pages 63-80 in A. Mwiturubani, and J.-A. van Wyk, editors. Climate change and natural resources conflicts in Africa. Institute for Security Studies, Pretoria, South Africa. [online] URL: https://issafrica.s3.amazonaws.com/site/uploads/Mono170. pdf

O'Hare, P., I. White, and A. Connelly. 2015. Insurance as maladaptation: resilience and the 'business as usual' paradox. Environmental and Planning C: Politics and Space 34:1175-1193. https://doi.org/10.1177/0263774X15602022

Ostrom, E. 1992. Covenants with and without a sword: selfgovernance is possible. American Political Science Review 86:404-417. http://dx.doi.org/10.2307/1964229

Ostrom, E. 2006. The value-added of laboratory experiments for the study of institutions and common-pool resources. Journal of Economic Behavior and Organization 61:149-163. http://dx.doi. org/10.1016/j.jebo.2005.02.008

Rapoport, A., D. V. Budescu, and R. Suleiman. 1993. Sequential requests from randomly distributed shared resources. Journal of Mathematical Psychology 37:241-265. http://dx.doi.org/10.1006/ jmps.1993.1015
Rapoport, A., and R. Suleiman. 1992. Equilibrium solutions for resource dilemmas. Group Decision and Negotiation 1:269-294. http://dx.doi.org/10.1007/BF00126266

Safarzynska, K. 2013. The coevolution of culture and environment. Journal of Theoretical Biology 322:46-57. http://dx. doi.org/10.1016/j.jtbi.2013.01.004

Schill, C., T. Lindahl, and A.-S. Crépin. 2015. Collective action and the risk of ecosystem regime shifts: insights from a laboratory experiment. Ecology and Society 20(1):48. http://dx.doi. org/10.5751/ES-07318-200148

Sigmund, K., H. De Silva, A. Traulsen, and C. Hauert. 2010. Social learning promotes institutions for governing the commons. Nature 466:861-863. http://dx.doi.org/10.1038/nature09203

Tan, J. H. W., and F. Bolle. 2007. Team competition and the public goods game. Economic Letters 96:133-139. http://dx.doi. org/10.1016/j.econlet.2006.12.031

Waring, T. M., M. A. Kline, J. S. Brooks, S. H. Goff, J. Gowdy, M. A. Janssen, P. E. Smaldino, and J. Jacquet. 2015. A multilevel evolutionary framework for sustainability analysis. Ecology and Society 20(2):34. http://dx.doi.org/10.5751/ES-07634-200234

Wolf, A. T. 2007. Shared waters: conflict and cooperation. Annual Review of Environmental Resources 32:241-269. http://dx.doi. org/10.1146/annurev.energy.32.041006.101434 


\section{Appendix 1. Theoretical Solution}

\section{A1. Resource uncertainty}

In this section, we propose a formal model of common-pool resources and examine the impact of shocks on harvesting. In each group, $n$ individuals $i$ decide simultaneously how much resources to harvest from the common-pool resource $R_{t}$. Individuals are allowed to harvest up to $x_{i t}<R_{t} / n$, where $x_{i}$ are harvests by individual $i$. The duration of the game is determined endogenously by collective decisions. In particular, the game ends in case resources become exhausted.

Total harvests $X_{t}$ is defined as a sum of harvests by $n$ individuals: $X_{t}=\sum_{i} x_{i t} \leq R_{t}$. Each period, a shock can diminish a fraction of resources $0<\theta_{t}<1$. A shock $z_{t}$ is drawn from the uniform distribution $U\left(\alpha_{1} \alpha_{2}\right)$ with some probability, which implies that $\theta_{t}=z_{t} / R_{t}$. We consider only negative shocks, which diminish resources. This is because of the fact that in the presence of positive events, resource conservation is not necessary to prevent group collapse.

Resource dynamics follow the logistic curve:

$$
R_{t+1}=(1-\theta)\left(R_{t}+\dot{R}_{t}\right)-X_{t}=(1-\theta)\left(R_{t}+r R_{t}\left(1-R_{t} / K\right)\right)-X_{t},
$$

where $0<r<1$ is the intrinsic growth rate of resources; $K$ is its carrying capacity; and $\dot{R}_{t}=r R_{t}\left(1-R_{t} / K\right)$ captures the natural growth or regeneration of resources. If a group runs out of resources $\left(R_{t}<1\right)$, subjects lose all their payoffs accumulated up to the moment of resource exhaustion. This creates a strong incentive to conserve resources. We use the condition $\left(R_{t}<1\right)$ instead of $\left(R_{t}<0\right)$ to avoid a situation when resources become negative as a result of a shock alone (regardless of harvesting decisions), i.e. in case resources are already close to exhaustion.

The utility of individual $i$ at time $t$ depends on his/her harvests:

$$
u_{i t}=\ln \left(x_{i t}\right)
$$

Subjects maximize the cumulative payoffs over time (see Antoniadou et al., 2013):

$$
\begin{aligned}
& V\left(R_{t}\right)=\max _{x, R_{t+1}} \sum_{t=0}^{\infty} \beta^{t} \ln \left(x_{i t}\right), \\
& \text { s.t. } R_{t+1}=\left(1-\theta_{t}\right)\left(R_{t}+\dot{R}_{t}\right)-X_{t},
\end{aligned}
$$

given the initial level of resources $R_{0}$, where parameter $\beta$ is the discount rate.

Equation $3 \mathrm{a}$ can be written as the Bellman equation with the state variable $R_{t}$, and the control variable $x_{i t}$ :

$$
V\left(R_{t}\right)=u_{i t}+p_{t}\left(\theta_{\mathrm{t}}, R_{t}, X_{t}\right) \beta E\left[V\left(R_{t+1}\right)\right]
$$




$$
\text { s.t. } R_{t+1}=\left(1-\theta_{t}\right)\left(R_{t}+\dot{R}_{t}\right)-X_{t} \text {, }
$$

where $p_{t}\left(\theta_{t}, R_{t}, X_{t}\right)$ is the probability that the game will continue to the next period (resources will not fall below 1).

The first order condition with respect to $R_{t+1}$ gives:

$$
-u_{i t}{ }^{\prime}\left(x_{i t}\right)+\beta p_{t} E\left[\frac{\partial V\left(R_{t+1}, \theta_{t+1}\right)}{\partial R_{t+1}}\right]=0 .
$$

By Envelope Theorem differentiating $V\left(R_{t+1}, \theta_{t+1}\right)$ with respect to $R_{t}$ gives:

$$
V^{\prime}\left(R_{t}\right)=u_{i t}{ }^{\prime}\left(x_{i t}\right)(1-\theta) \frac{\partial\left(R_{t}+\dot{R}_{t}\right)}{\partial R_{t}} .
$$

We take one step forward for (6) and apply it into (5), to derive:

$$
u_{i t}{ }^{\prime}\left(x_{i t}\right)=(1-\theta) \beta p_{t} E\left[u_{i t+1}{ }^{\prime}\left(x_{i t+1}\right) \frac{\partial\left(R_{t+1}+\dot{R}_{t+1}\right)}{\partial R_{t+1}}\right],
$$

which leads to:

$$
1 / x_{i t}=\beta(1-\theta) p_{t}\left(1+r-2 r \frac{R_{t+1}}{K}\right)\left(1 / x_{i t+1}\right)
$$

Using equations 1 and 8, the model can be reduced to the system of equations :

$$
\begin{aligned}
& X_{t+1}=X_{t} \beta(1-\theta) p_{t}\left(1+r-2 r \frac{R_{t+1}}{K}\right), \\
& R_{t+1}=(1-\theta)\left(R_{t}+r R_{t}\left(1-R_{t} / K\right)\right)-X_{t} .
\end{aligned}
$$

The equilibrium of the above system can be derived, using conditions $R_{t+1}=R_{t}, X_{t+1}=X_{t}$, and assuming that $p_{t}=p$, as:

$$
\begin{gathered}
X^{*}=\frac{K\left(-1+2 \beta p-\beta^{2} p^{2}(1+r)(1-\theta)(1-r(1-\theta)+\theta)\right.}{4 \beta^{2}(1-\theta) p^{2} r}, \\
R^{*}=\frac{K(\beta p(1-\theta)(1+r)-1)}{2 \beta(1-\theta) p r} .
\end{gathered}
$$

In two other solutions, subjects harvest nothing in the equilibrium $\left(X^{*}=0\right)$. Solution (10) implies that the share of resources harvested in the equilibrium:

$$
X * / R^{*}{ }_{\text {shocks }}=\frac{1-\beta p(1-r+r \theta+\theta)}{2 \beta p} .
$$

Increasing $\theta$ decreases the fraction of harvested resources in (11). Thus, we expect that shocks promote resource conservation in the equilibrium: 


$$
\left(X * / R^{*}\right)_{\text {baseline }}=\frac{1-\beta p(1-r)}{2 \beta p}>\left(X^{*} / R^{*}\right)_{\text {shocks }}=\frac{1-\beta p(1-r+r \theta+\theta)}{2 \beta p} .
$$

In the absence of shocks, we expect subjects to harvest the fraction of resources $\left(X^{*} / R^{*}\right)_{\text {baseline }}=\frac{1-\beta p(1-r)}{2 \beta p}=\frac{1-0.99(1-0.1)}{2 * 0.99}=0.055$, assuming $\mathrm{p}=1$ and $\beta=0.99$. This is more than the social optimum, which requires that resources remain at their half capacity $K / 2$, while group members consume the renewal rate of resource $\left(X{ }_{t}=r K / 4\right)$. This in turn implies the socially optimal fraction of harvested resources is equal to $(2 / 3) / 40=0.02<0.055$. If resources are below the maximum sustainable growth (for instance because of shocks), it would be beneficial for individuals to reduce their harvests so as to give the resource time to renew itself and reach the optimal level.

The impact of shocks in the equilibrium on model dynamics can differ from their impact outside the equilibrium. Figure A1.1 illustrates dynamics of the dynamical system described in (9), using parameter values as in the experiment. In the figure, we compare model predictions in the baseline and shock scenarios. We assume that initial harvests are equal to 3 in the numerical analysis. Increasing this value fosters resource depletion. Figure A1.1(a) illustrates that groups are expected to harvest a larger fraction of resources, the more severe the shocks are. However, this result is driven by the fact that resources are diminished by shocks under resource uncertainty. In fact, from equation 9(a) it follows that larger $\theta$ implies that subjects harvests less resources for the same size of the resource. This is supported by Figure A1.1(b), which depicts the fraction of harvested resources over time for different values of the resource. 


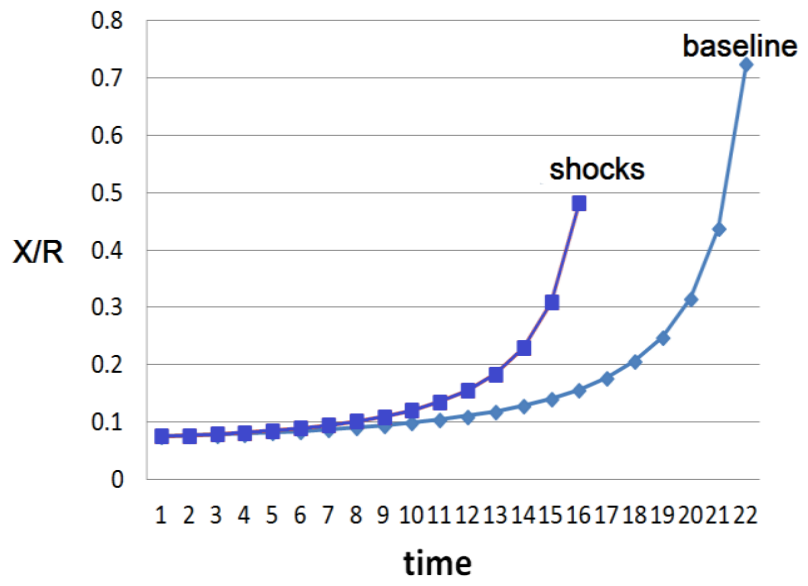

(a) harvests over time

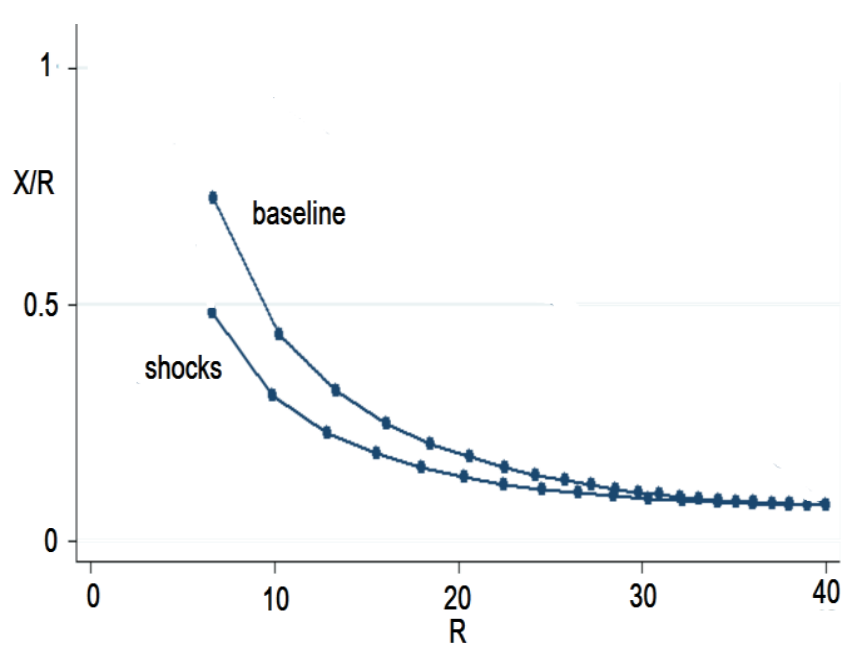

Figure A1.1 The fraction of resources harvested over time. Parameter values used in the figure: K=80, $r=0.1$, $R_{0}=45, \beta=0.99$ correspond to parameters used in the experiment. We assume shocks to be equal to the expected value of shocks in the experiment: $z_{t}=1$ in the shock treatment; and $z_{t}=0$ in the baseline.

\section{A2.Intergroup sharing}

In the sharing treatment, after harvesting decisions, subjects can decide whether to send some of their harvests to augment resources of the partner group. Let's assume that subjects share a fraction of their harvests in anticipation that members of the partner group would do the same. In the presence of intergroup sharing, the utility of individual $i$ equals:

$$
u_{i t}=\ln \left(x_{i t}(1-c)\right),
$$

where $c$ is the fraction of his/her harvest shared with the outgroup members.

Subjects maximize the cumulative payoffs over time:

$$
\begin{aligned}
& V\left(R_{t}\right)=\max _{x, R_{t+1}} \sum_{t=0}^{\infty} \beta^{t} \ln \left(x_{i t}(1-c)\right), \\
& \text { s.t. } R_{t+1}=R_{t}+\dot{R}_{j t}-X_{t}+c Y_{t},
\end{aligned}
$$

where $Y_{t}$ is the total harvest in the partner group.

The system can be described by equations (derived analogously to equations $9 \mathrm{a}$ and $\mathrm{b}$ ):

$$
\begin{aligned}
& (1-c) X_{t+1}=(1-c) X_{t} \beta p_{t}\left(1+r-2 r \frac{R_{t+1}}{K}\right), \\
& R_{t+1}=R_{t}+r R_{t}\left(1-R_{t} / K\right)-X_{t}+c Y_{t} .
\end{aligned}
$$




\section{A3. Collective versus individual donations to the outgroup}

We compare the frequency of individual versus collective contributions to the outgroup. By individual contributions we refer to the situation where only one participant shared her harvests with the outgroup at time $t$. In turn, collective contributions describe the situation, when more than one individual donated resources. Figure A1.2 compares the frequency of collective contributions and the total number of periods, during which at least one subject donated harvests to the outgroup. The figure illustrates that the more often groups share resources, the higher the percentage of collective contributions is.

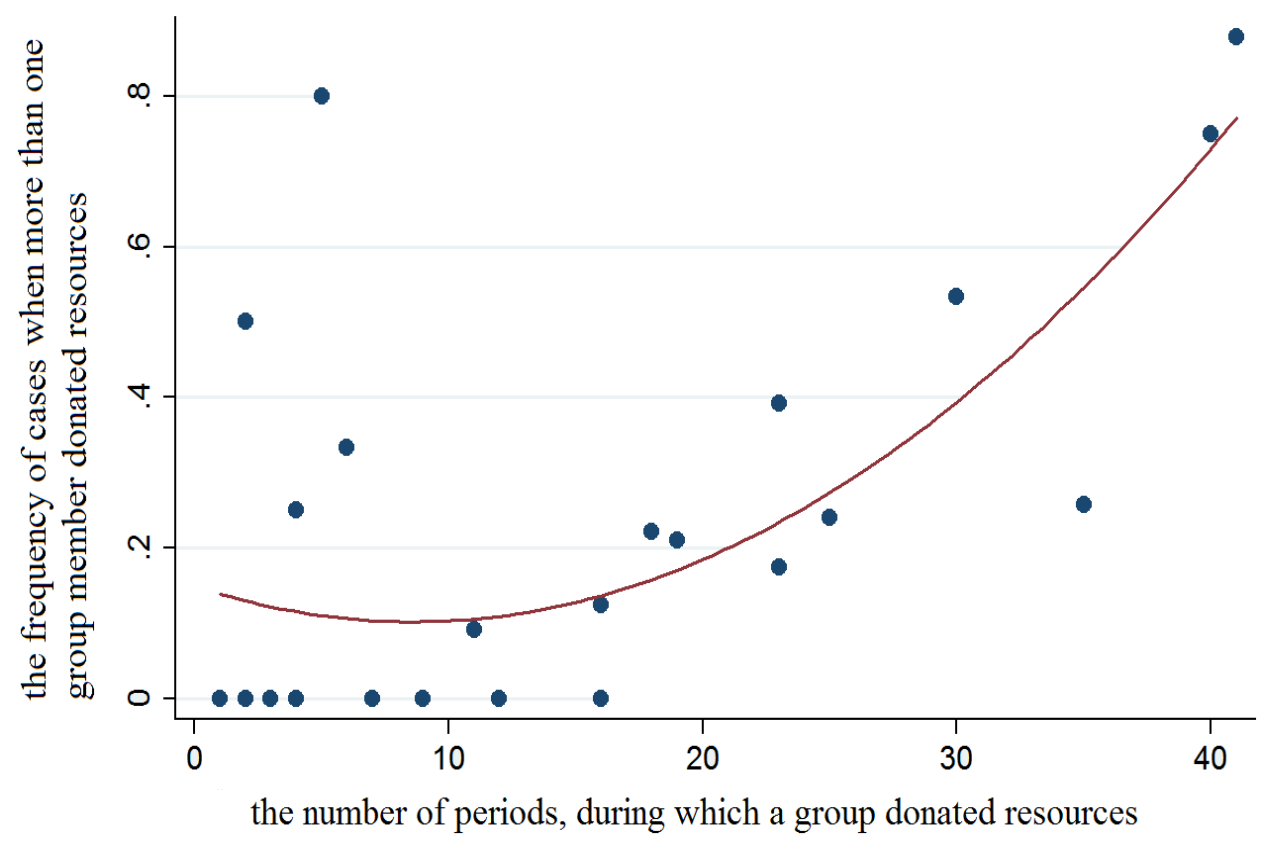

Figure A1.2 The frequency of intergroup sharing versus collective donations. 


\section{Appendix B}
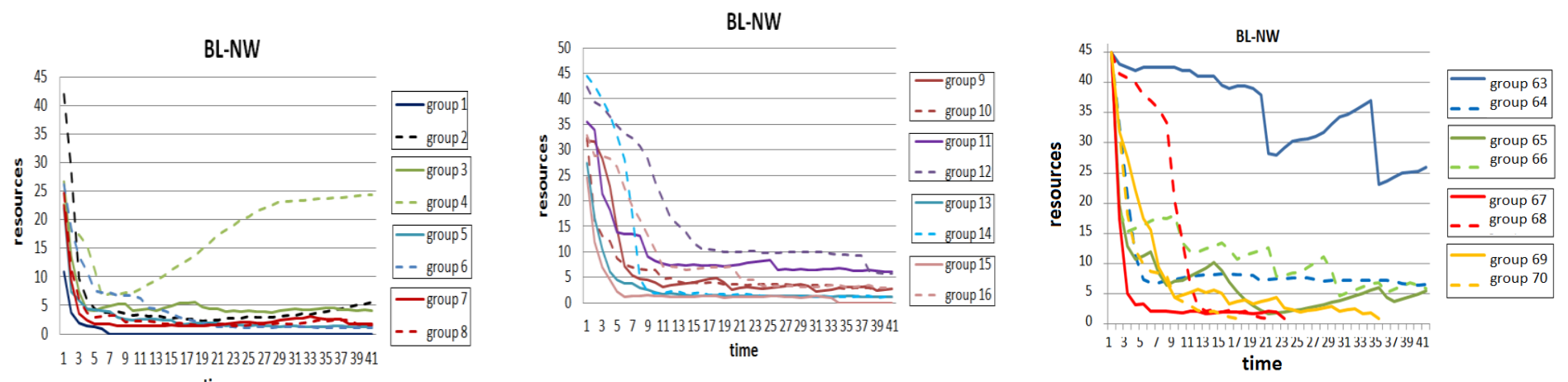

(a) The baseline treatment
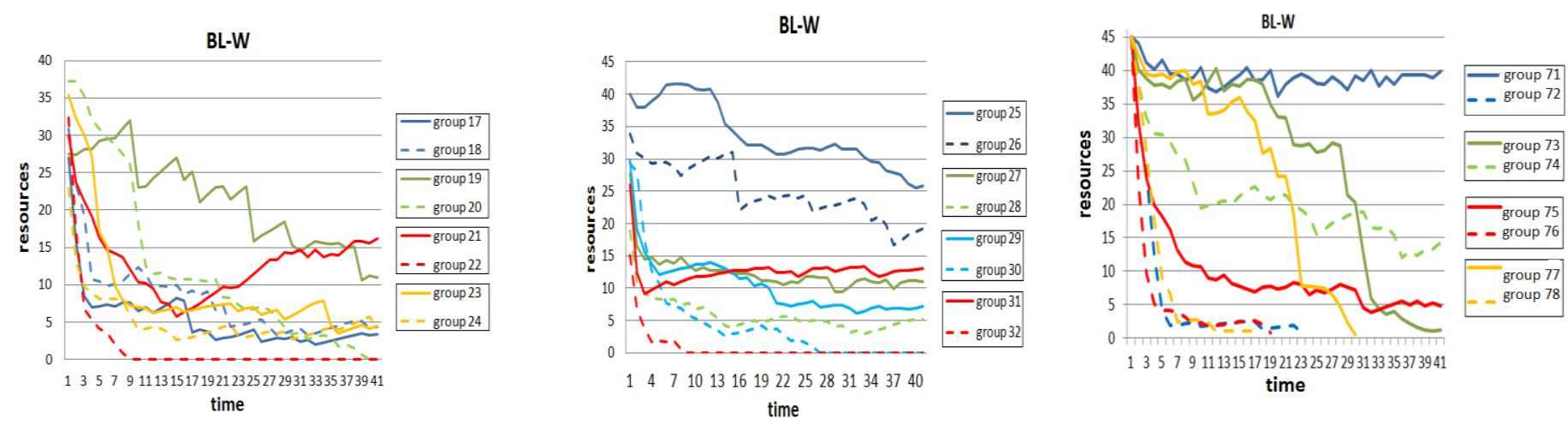

(b) The shock treatment
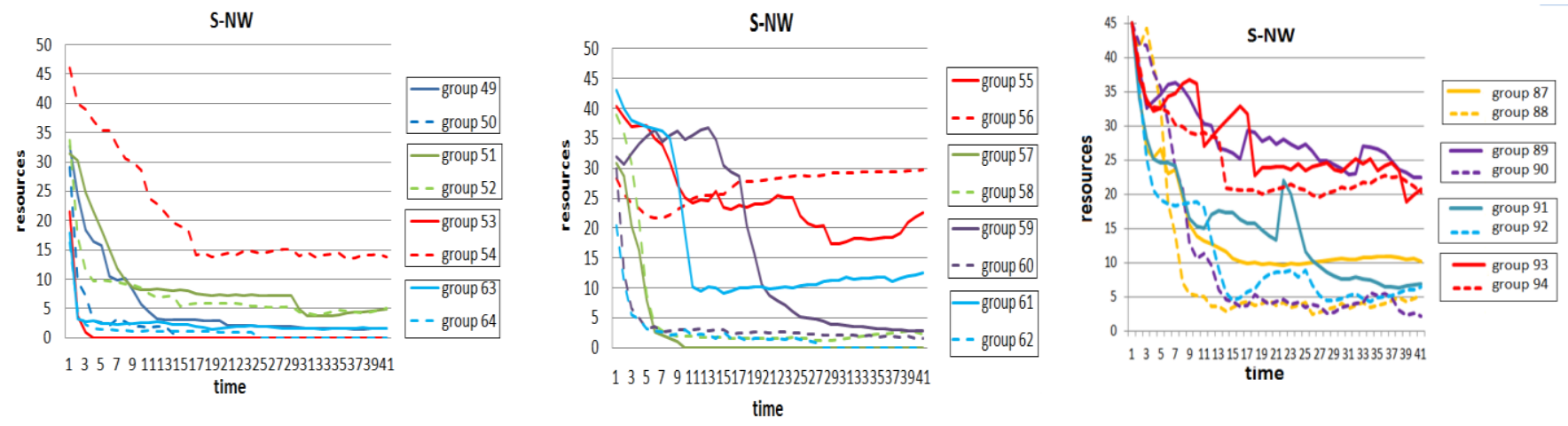

(c) The sharing treatment

Figure B1.1 Availability of resources at a given period. Boxes indicate interacting groups, i.e. partners. To increase visibility we depict 4 partner groups per figure. Figures on the right show results from the sample of subjects from the University of Vienna. 


\section{Appendix B. Instructions}

All

\section{Welcome}

You are now taking part in a decision-making experiment. Depending on your decisions and decisions made by others, you may be able to earn a substantial amount of money.

The experiment consists of three parts. In the first part, we will ask you to answer questions which will appear on your screen. Once everybody has answered them, we will distribute a set of instructions. Afterwards, the second part of the experiment will start, during which you can learn dynamics of the game. The third part - of the actual experiment - will follow afterwards with some additional elements. This part will last much longer than the second part. We will distribute instructions for this part prior to its beginning. 


\section{Part 2}

During this part of the experiment, you will have a chance to learn dynamics of the game. You will be matched with 2 other participants to collect tokens from the common pool of tokens. Your group starts with the common pool of 45 tokens.

You will not know who is who in your group during or after the experiment. Every member of your group, including you, will decide simultaneously on the number of tokens to collect. The number of tokens collected by each person cannot exceed $33 \%$ of all tokens available to the group. You will be informed about how many tokens were collected by others in your group. The decisions of group members will be displayed in a random order every period - it will not be possible to determine who collected how many tokens.

The total number of tokens collected by the group will be subtracted from the common pool of tokens. Then, depending on the number of tokens left in the common pool, there will be a re-growth in the number of tokens (RG), according to:

$$
\mathrm{RG}=0.1 * \mathrm{TC} *(1-\mathrm{TC} / 80)
$$

where TC is the number of tokens in the pool, and 80 is the maximum carrying capacity of the pool of tokens, i.e. beyond which the number of tokens will not increase further.

The graph below illustrates an increase in the number of tokens (RG) in the common pool, depending on the number of tokens in the common pool (TC):

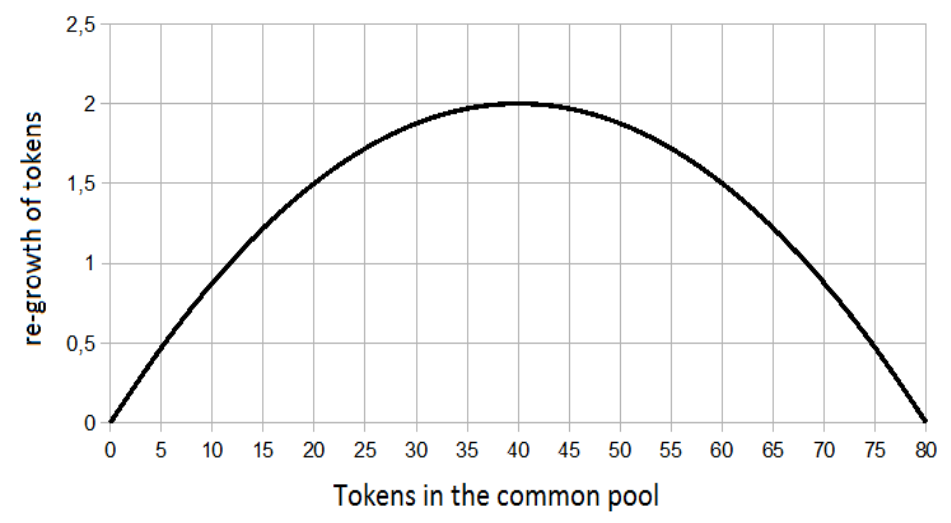


For instance, if the number of tokens in the common pool is 40 , then the expected re-growth of tokens is 2 , and there will be 42 tokens available to your group in the next period.

You will be asked to collect tokens for some periods. However, this part of the experiment may also end if the number of tokens in the common pool of tokens goes below 1 [one]. In this case, everyone is your group looses all their tokens.

\section{Your Earnings:}

The aim of this part of the experiment is to give you the opportunity to learn dynamics of the game. You will not earn money.

\section{Timing:}

There is another important note. You will have a limited but a sufficient amount of time (some seconds) to decide how many tokens to collect. If you exceed this time, the decision will be taken for you.

\section{Before starting:}

In order to check if you understand these instructions, please answer questions which will appear on your screen. 


\section{The baseline treatment}

\section{Part 3}

In this part of the experiment, you will be asked to collect tokens for many periods - just as you did before. You will be randomly matched with 2 new participants, thus you will interact with different players than in part 2 of the experiment.

Your Earnings:

Your earnings will be equal to the number of tokens, which you collected. Each token is worth $0.5^{1}$ Euro.

There is, nevertheless, an exception: if the number of tokens in the common pool goes below 1 [one], everyone in your group will lose all their tokens. In this case, your earnings will be zero in this part of the experiment.

${ }^{1}$ During the experiment conducted at the University of Warsaw, each token was worth 1.5 złotych. 


\section{The shock treatment}

\section{Part 3}

In this part of the experiment, you will be asked to collect tokens for many periods - just as you did before. You will be randomly matched with 2 new participants, thus you will interact with different players than in part 2 of the experiment. In addition, there is the possibility of a random event occurring, which can be thought of as a shock destroying tokens in the common pool.

The random event:

In this part of the experiment, there is $33 \%$ of chances that your group will lose between 0.5 and 1.5 tokens due to a random event.

Your Earnings:

Your earnings will be equal to the number of tokens, which you collected. Each token is worth 0.5 Euro.

There is, nevertheless, an exception: if the number of tokens in the common pool goes below 1 [one], everyone in your group will lose all their tokens. In this case, your earnings will be zero in this part of the experiment. 


\section{The sharing treatment}

\section{Part 3}

During this (last) part of the experiment, you will be asked to collect tokens for many periods - just as you did before. You will be randomly matched with 2 new participants, thus you will interact with different players than in part 2 of the experiment.

In this part of the experiment, your group will be matched with another group in the room. We will refer to this group as a "partner group". During the experiment, you can observe choices made by others in your group and also choices made by others in the partner group. Members of the partner group will collect tokens from their own common pool of tokens.

After collecting decisions take place, you can decide whether you want your group to share some tokens from your total tokens (tokens which you collected up to this time) with the partner group.

\section{Sharing}

After everyone has decided how many tokens to collect, you will be asked to indicate how many tokens you would like to share with the partner group.

Precisely, you will be asked to indicate how many tokens from your total tokens you would like to send to the partner group. If you do not wish to share tokens write 0 . The amount of tokens taken from you will be added to the pool of tokens of the partner group. These tokens will be subtracted from your total tokens.

Members of the partner group will be also asked whether they would like to share some of their tokens with your group.

\section{Your Earnings:}

Your earnings will be equal to the number of tokens, which you collected. Each token is worth 0.5 Euro.

There is, nevertheless, an exception: if the number of tokens in the common pool goes below 1 [one], everyone in your group will lose all their tokens. In this case, your earnings will be zero in this part of the experiment.

If the number of tokens in the common pool of the partner groups goes below 1 [one], members of this group will lose all their tokens. They will not participate in the experiment any longer. Afterwards, there will be no voting decisions in your group. 


\section{Sharing + Shocks}

\section{Part 3}

During this (last) part of the experiment, you will be asked to collect tokens for many periods - just as you did before. You will be randomly matched with 2 new participants, thus you will interact with different players than in part 2 of the experiment.

In this part of the experiment, your group will be matched with another group in the room. We will refer to this group as a "partner group". During the experiment, you can observe choices made by others in your group and also choices made by others in the partner group. Members of the partner group will collect tokens from their own common pool of tokens.

Every period after collecting decisions take place, you can decide whether you want to share some tokens from your total tokens (i.e. tokens which you collected up to the time of sharing decision) with the partner group.

In addition, after collecting and sharing decisions, there is also the possibility of a random event occurring, which can be thought of as a shock destroying tokens in the common pool.

\section{Sharing}

After everyone has decided how many tokens to collect, you will be asked to indicate how many tokens you would like to share with the partner group.

Precisely, you will be asked to indicate how many tokens from your total collected tokens you would like to send to the partner group. If you do not wish to share tokens write 0 . The amount of tokens taken from you will be added to the pool of tokens of the partner group. These tokens will be subtracted from your total collected tokens.

Members of the partner group will be also asked whether they would like to share some of their tokens with your group.

The random event:

In this part of the experiment, there are $33 \%$ of chances that your group will lose between 0.5 and 1.5 tokens due to a random event. The partner group faces the same probability of a random event occurring. 


\section{Your Earnings:}

Your earnings will be equal to the number of tokens which you collected minus the tokens you shared with the other group. Each token is worth 0,5 Euro.

There is, nevertheless, an exception: if the number of tokens in the common pool goes below 1 [one], everyone in your group will lose all their tokens. In this case, your earnings will be zero in this part of the experiment.

If the number of tokens in the common pool of the partner groups goes below 1 [one], members of this group will lose all their tokens. They will not participate in the experiment any longer. Afterwards, there will be no voting decisions in your group. 


\section{Appendix C. Measurements of other-regarding preferences, IQ and risk aversion}

\section{PRE-EXPERIMENT QUESTIONS}

\section{DICTATOR GAME}

You are matched with a person in this room. You have 1 Euro.

How many cents would you like to share with this person?

\section{TRUST GAME}

You are matched with another (different) person. You have 1 Euro. How many cents would you like to send him/her? For every cent you send, the person will receive a double value of this amount. He or She will be asked to send you some money back (as he or she wishes), keeping the rest for himself.

\section{TRUSTWORTHINESS}

A person (different from the preview two) in this room sends you $\mathrm{x}$ cents. You can send back between 0 and $\mathrm{x}$ cents. How many cents would you like to send back?

\section{RISK-LOVING}

You have 1 Euro. You have the possibility of investing some cents in a project. The project has $40 \%$ of probabilities of being successful. If the project is successful, you will receive the invested amount multiplied by 3. You will also keep cents which you have invested. If the project fails, you only keep cents, which you have not invested. How many cents would you like to invest in the project?

\section{COGNITIVE SKILLS (IQ)}

You have 20 seconds to respond to the following questions. For each correct answer you earn 25 cents.

a) Which number comes next?

$3,5,8,13,21, \ldots$

b) Which number is missing?

$\begin{array}{lll}1 & 4 & 3 \\ 5 & 9 & 4 \\ 4 & 5 & \ldots\end{array}$

c) Which number comes next?

$4,54,654, \ldots$ 
b) Which number is missing?

$\begin{array}{llll}17 & 8 & 5 & 4 \\ 13 & 7 & 5 & 4 \\ 10 & 6 & 4 & \ldots\end{array}$

\section{POST-EXPERIMENT QUESTIONNAIRE}

1. Are you: (Male /Female)

2. Nationality

3. Are you a undergraduate student or a master student

4. In you are an undergraduate student, in which year of study are you currently? $(1,2,3,4,5)$

5. Which is your major: (Economics / Business, Management / A Social Science / Natural Science, Mathematics, etc, / Art, Language, Humanities / Others)

6. How would you describe the income of your parents from 1 to 7 where $1=$ low and $7=$ high

7. How much money do you spend every month (apartment, food, clothes...)?

8. How would you describe your political preferences from 1 to 7 where $1=$ very right-wing and $7=$ very leftwing?

9. Before the experiment, how long did you expect that the experiment would last?

Additional questions: Only after treatments with sharing:

How much do you agree with the following statements?

10. Before the experiment, I expected that the partner group would share some resources with us in case we had few tokens in our pool because of my group collecting too many tokens: 0 completely disagree -4 completely agree

11. Before the experiment, I expected that the partner group would share some resources with us in case shocks destroyed tokens in our pool: 0 completely disagree -4 completely agree 